\title{
Keratin-Based Nanoparticles as Drug Delivery Carriers
}

\author{
Claudia Ferroni *(D) and Greta Varchi *(D) \\ Institute of Organic Synthesis and Photoreactivity-ISOF, Italian National Research Council, 40129 Bologna, Italy \\ * Correspondence: claudia.ferroni@isof.cnr.it (C.F.); greta.varchi@isof.cnr.it (G.V.); \\ Tel.: +39-051-639-8286 (C.F.); +39-051-639-8283 (G.V.)
}

check for updates

Citation: Ferroni, C.; Varchi, G. Keratin-Based Nanoparticles as Drug Delivery Carriers. Appl. Sci. 2021, 11, 9417. https://doi.org/10.3390/ app11209417

Academic Editor: Chang Ming Charlie Ma

Received: 10 September 2021 Accepted: 29 September 2021 Published: 11 October 2021

Publisher's Note: MDPI stays neutral with regard to jurisdictional claims in published maps and institutional affiliations.

Copyright: (c) 2021 by the authors. Licensee MDPI, Basel, Switzerland. This article is an open access article distributed under the terms and conditions of the Creative Commons Attribution (CC BY) license (https:// creativecommons.org/licenses/by/ $4.0 /)$.

\begin{abstract}
Keratin is a structural protein of mammalian tissues and birds, representing the principal constituent of hair, nails, skin, wool, hooves, horns, beaks, and feathers, and playing an essential role in protecting the body from external harassment. Due to its intrinsic features such as biocompatibility, biodegradability, responsiveness to specific biological environment, and physical-chemical properties, keratin has been extensively explored in the production of nanocarriers of active principles for different biomedical applications. In the present review paper, we aimed to give a literature overview of keratin-based nanoparticles produced starting from human hair, wool, and chicken feathers. Along with the chemical and structural description of keratin nanoparticles, selected in vitro and in vivo biological data are also discussed to provide a more comprehensive framework of possible fields of application of this protein. Despite the considerable number of papers describing the production and use of keratin nanoparticles as carries of anticancer and antimicrobial drugs or as hemostatic and wound healing materials, still, efforts are needed to implement keratin nanoparticles towards their clinical application.
\end{abstract}

Keywords: human hair keratin; wool keratin; chicken feathers keratin; nanoparticles preparation; drug delivery; water purification; tumor-responsiveness

\section{Introduction}

The synthesis and discovery of novel and more potent drugs have represented the primary driver of pharmaceutical companies for a long time. Nevertheless, increasing evidence demonstrates that drugs potency is not directly correlated with their therapeutic benefit. In most cases, drug formulation and delivery systems have been revealed to be essential for controlling and improving efficacy, safety, bioavailability, pharmacokinetic, biodistribution, and clearance [1]. However, effective drug delivery is still challenging primarily because of our limited knowledge of biological barriers and their interaction with drugs' carriers [2]. On this basis, enormous efforts have been dedicated to developing suitably designed and effective drug delivery systems based on biomaterials, owing to their biocompatibility, biodegradability, non-immunogenicity, ease of production and up-scaling, and reproducibility [3].

Among naturally occurring biomaterials, proteins represent one of the most valuable categories for producing drugs nanocarriers due to their abundance, biodegradability, low immunogenicity, non-toxicity, and biocompatibility [4]. In addition, because of their defined primary structure, the production of protein-based nanocarriers can be properly implemented through pre- or post-functionalization, enabling the covalent attachment of drugs, targeting moieties, dyes, and diagnostic elements, as well as the incorporation of different agents by exploiting the protein hydrophobic and hydrophilic domains.

Among the various proteins used for nanocarrier fabrication, the last decade has witnessed an increasing interest in the use of keratin as a promising and versatile biopolymer for nanoparticle preparation. Keratin is a structural protein present in mammalian tissues (hair, fur, nails, skin, wool, hooves, and horns), and birds (e.g., bird beaks and feathers), playing an important role in protecting the body from external harassment. The keratin 
content in mammalian hair (such as human hair and wool) and bird feathers exceeds $80 \%$ [5].

Keratin is a cysteine-rich fibrous protein, structurally divided into $\alpha$-keratins and $\beta$-keratins. $\alpha$-keratins are the primary constituent of soft tissues such as wool, hair, hooves, nails, horns, and the stratum corneum, whereas harder $\beta$-keratins are present in feathers, avian claws and beaks, reptilian claws, and scales. The significant presence of disulfide and hydrogen bonds confers to keratin some appealing mechanical properties, such as strength, stability, rigidity, and resistance to proteolytic degradation. Furthermore, keratin is characterized by unique aminoacidic sequences, such as "Arg-Gly-Asp" (RGD) and "Leu-Asp-Val" (LDV), that specifically bind vitronectin integrin receptors which, for instance, are overexpressed by several cancer cells. Therefore, keratin could represent a remarkable breakthrough in the field of cancer nanomedicine [6].

To increase its poor water solubility, several methodologies have been investigated and setup, allowing the extraction of keratin from different sources. Extraction can be achieved only by cleavage of disulfide covalent bonds and hydrogen inter-chain bonds, and the so far known extracting procedures can be divided into denaturing and hydrolyzing methods $[7,8]$. Denaturing processes allow for obtaining keratin with its native molecular weight distribution and amino acid composition. On the other hand, hydrolyzing processes (acidic, alkaline, enzymatic, and ionic liquid hydrolysis) give access to the isolation of a mixture of low molecular weight proteins and polypeptides, both having negligible sulfur content.

The thorough analysis of keratins structure, distribution, and extraction from different sources will not be discussed in the present report, being already exhaustively reviewed by other authors in reviews and book chapters [7,9-14].

The purpose of the current contribution is the description and discussion of keratinbased nanoparticles for drug delivery purposes. In particular, keratin nanocarrier production of different origins will be described along with available biological data.

\section{Keratin-Based Nanoparticles}

One of the more widely explored applications of keratin as a drug carrier involves the encapsulation of therapeutics into keratin-based nanoparticles (KNPs). Indeed, KNPs have shown fascinating properties, such as high surface area, tunable biodegradability, excellent biocompatibility, and easy functionalization, thus making them effective and promising platforms for controlled and targeted drug delivery. KNPs are obtained from human hair, wool, and chicken feathers using a broad variety of techniques, including electrospray [15], ionic gelation [16], self-assembly [17], drug-induced aggregation [18], desolvation [19], nanoprecipitation [20], etc. They are found to have a plethora of biological and environmental applications, such as cancer treatment, tissue engineering, wound healing, and the removal of hazardous substances from wastewater (heavy metal ions, antibiotics etc.) $[7,21]$. In the following sections, we report an account of papers describing the use of keratins to produce KNPs, discriminating between the different keratin sources, e.g., hair, wool, and chicken feathers. In the last part, a critical overview of this topic and possible future challenges is provided.

\subsection{Human Hair Keratin-Based Nanoparticles}

Human hair is considered a useless material, being usually discarded as waste. In rural and in urban, highly populated areas, tons of hair are either disposed in the land or collected in the waste streams, posing several issues. In fact, due to its composition and slow degradation rate, hair remains for a long period of time, contributing to an increased nitrogen concentration in soil and water. At the same time, if disposed by incineration, hair produces toxic gases such as ammonia, carbonyl sulfides, hydrogen sulfides, sulfur dioxide, phenols, nitriles, pyrroles, and pyridines, that significantly increase pollution [22].

However, the unique properties of human hair, such as chemical composition, slow degradation rate, high tensile strength, thermal insulation, elastic recovery, and exceptional 
interaction with water and oils, make it a valuable material for different applications, such as production of fertilizers, hair extensions, musical instruments, hair brushes, etc. [10]. Besides the use of human hair per se, keratin, representing the hair's major constituent, has attracted increasing attention as a biomaterial for biomedical applications $[7,23]$.

In 2016, Brown et al. studied the use of keratin extracted from hair, under reductive Shindai's conditions [24], that was further covalently functionalized with epigallocatechin (ECGG) trough formaldehyde bridges [25]. The effective EGCG-keratin conjugation was confirmed by the authors through different spectroscopic techniques, e.g., UV-Vis and IR spectroscopy, NMR (Figure 1), and XPS. EGCG-functionalized keratin was then assembled to form spherical nanoparticles, namely NANO, with a hydrodynamic diameter of $50 \mathrm{~nm}$ and a polydispersity index of 0.12 , as potential antioxidant and radical scavenging materials.

$\mathbf{a}$

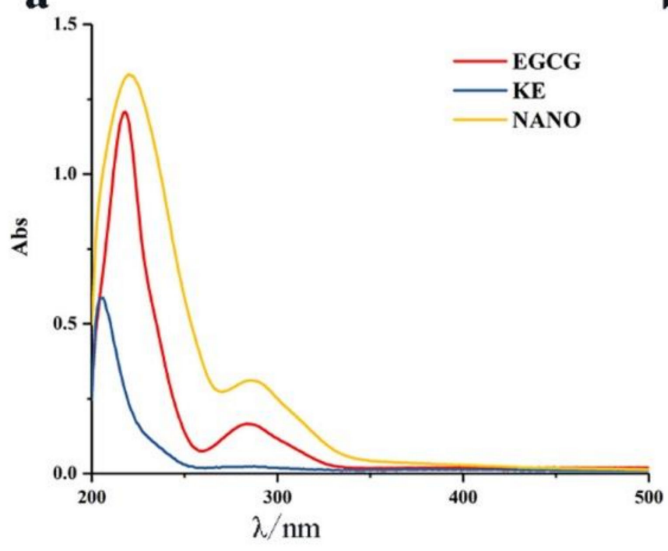

c

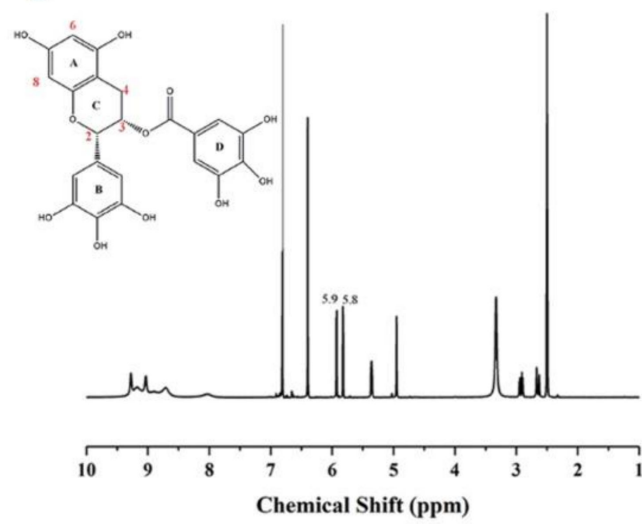

b

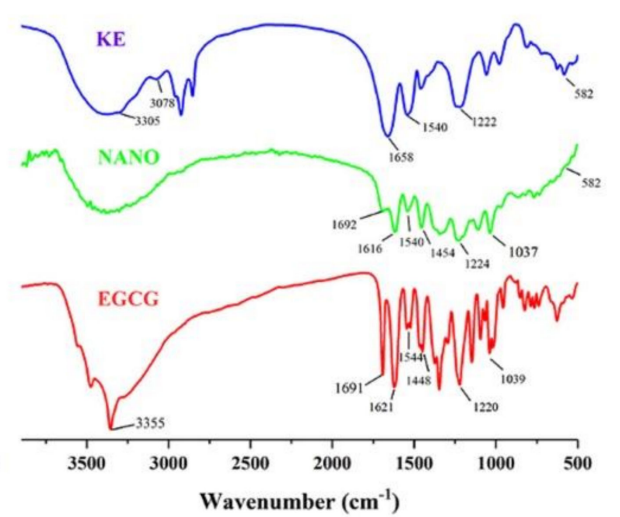

d

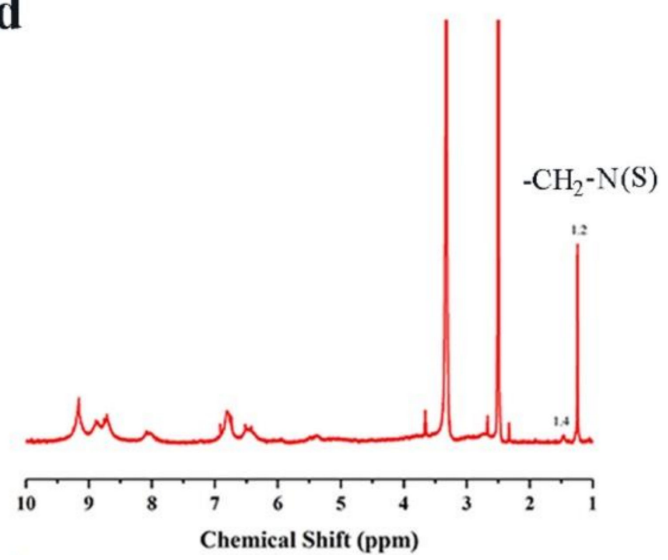

Figure 1. Comparative (a) UV-Vis spectra and (b) FTIR spectra of NANO, free EGCG, and keratin. (c) ${ }^{1}$ HNMR spectra of EGCG and (d) of NANO. Reprinted and adapted with permission from [25]. Copyright 2021 American Chemical Society.

The scavenging ability of NANO was assessed by the authors with two different probes, e.g., 1,1-Diphenyl-2-picrylhydrazyl (DPPH) and 2,2'-azino-bis(3-ethylbenzothiazo line-6-sulfonic acid) (ABTS). At the highest concentration, free EGCG, vitamin C, and NANO showed a comparable DPPH ${ }^{\bullet}$ scavenging ability (ca. 93\%) (Figure 2a); conversely, the $\mathrm{ABTS}^{\bullet+}$ scavenging rate of NANO was lower than free EGCG but much higher than vitamin $C$ (Figure $2 \mathrm{~b}$ ). Indeed, at a concentration of $7.5 \mu \mathrm{g} / \mathrm{mL}$, the scavenging rate of NANO, EGCG, and vit $C$ was $93.6 \%, 100 \%$, and $67.1 \%$, respectively.

The toxicity of NANO on cell proliferation was evaluated on mouse fibroblast (L929) and on human umbilical vein endothelial (HUVEC) cell lines, showing that they are nontoxic for a concentration of up to $20 \mathrm{mg} / \mathrm{mL}$. The authors also investigated the protective effect of NANO towards macrophages, indicating that nanoparticles efficiently reduce 
excesses of reactive oxygen species (ROS) by increasing the activity of intracellular antioxidant enzymes, such as superoxide dismutase (SOD), and GSH. Importantly, keratin-EGCG nanoparticles displayed good anti-inflammatory effects by reducing the release of cellular nitric oxide (NO) and pro-inflammatory factors (TNF- $\alpha$ and IL-1 $\beta$ ), thus reducing the lipopolysaccharide (LPS)-mediated inflammation. Overall, the work by Li and coworkers demonstrates that human hair keratin-EGCG nanoparticles are promising systems for the protection of cells from inflammation due to imbalanced ROS/NOS production.
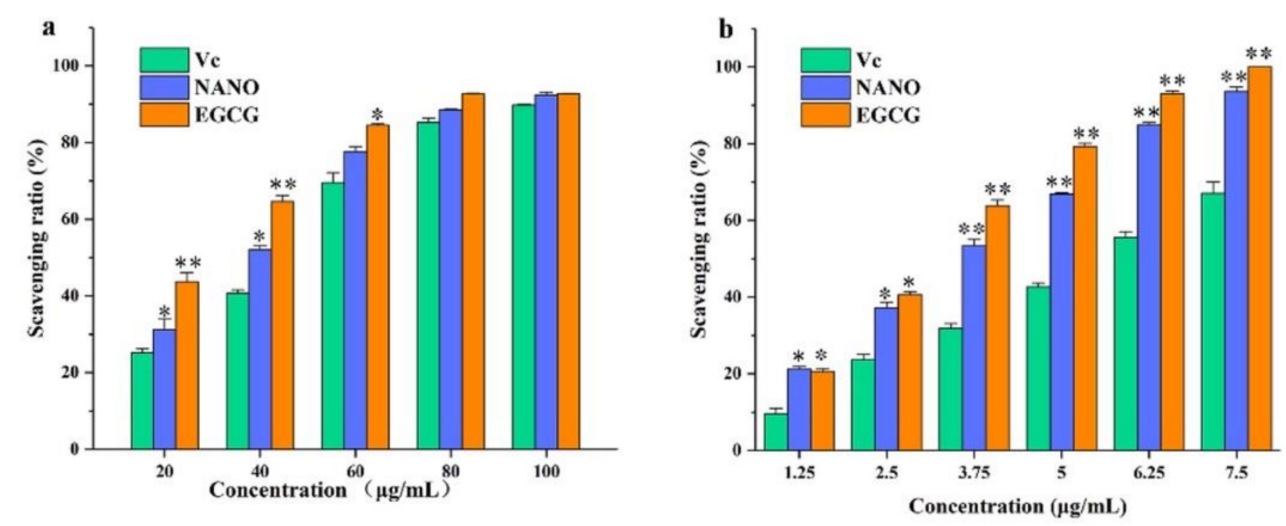

Figure 2. (a) DPPH and (b) ABTS radical scavenging activities of vitamin C, NANO, and EGCG at different concentrations. The "**, and "***" represent $p<0.05$, and $p<0.01$. Reprinted and adapted with permission from [25]. Copyright 2021 American Chemical Society.

Human hair keratin intrinsic responsiveness to $\mathrm{pH}, \mathrm{GSH}$, and trypsin was exploited by Yuan and colleagues to fabricate drug carriers where keratin/poly-dopamine (PDA) complexes functioned as gatekeepers of mesoporous silica nanoparticles (MSNs) [26]. In more detail, PDA was self-polymerized and complexed with iron (III), followed by conjugation with keratin. According to the authors, the PDA/keratin coating of MSNs could reduce their toxicity by limiting the interaction with cells membranes, thus allowing the system to reach the tumor environment where, thanks to the presence of elevated GSH concentration, the PDA/keratin coating would be degraded, allowing the release of the MSN's cargo. The responsiveness of MSNs@PDA@keratin nanoparticles was evaluated at different $\mathrm{pH}$ and GSH concentrations, showing that nanoparticles size dramatically increased both under acidic and reductive conditions $(\mathrm{pH}=5$; GSH $10 \mathrm{mM})$, while the zeta potential switched from negative to positive, most likely due to the sulfhydryl-disulfhydryl exchange reaction. Finally, to further prove the potential of their system, the authors loaded the anticancer drug doxorubicin (DOX) onto MSNs@PDA@keratin nanoparticles (see Section 2.1.1).

In 2020, Gnanamani reported a study where keratin and albumin were used to improve the biocompatibility and storage stability of gold nanoparticles (AuNPs) [27]. The authors prepared blank AuNPs, keratin-functionalized AuNPs (KP-AuNPs), albuminfunctionalized AuNPs (AP-AuNPs), and keratin-albumin-functionalized AuNPs (KP-APAuNPs) by mixing an aqueous solution of $0.01 \mathrm{M} \mathrm{HAuCl}_{4} \cdot 3 \mathrm{H}_{2} \mathrm{O}$ with the proteins dissolved in water at different concentrations (Figure 3).

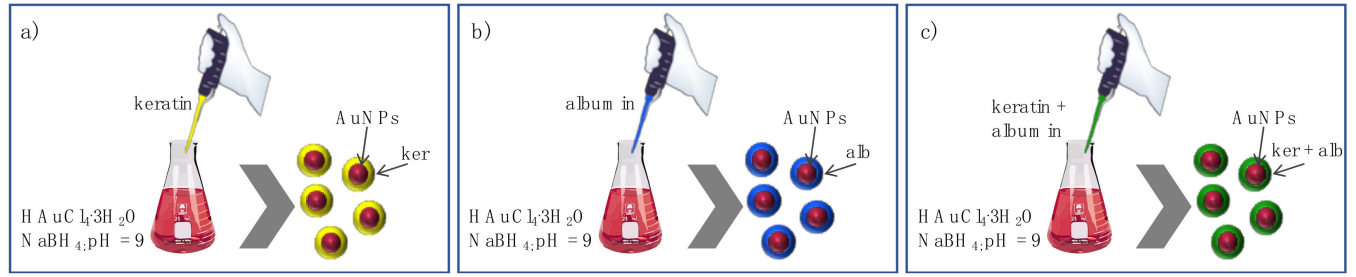

Figure 3. Schematic preparation procedure of (a) KP-AuNPs, (b) AP-AuNPs, and (c) KP-AP-AuNPs. 
The successful AuNPs functionalization was confirmed through various characterization techniques, and results revealed that the interaction between the proteins and the AuNPs surface through cysteine and amine groups ultimately determines a significant size increase (from $38 \mathrm{~nm}$ till $590 \mathrm{~nm}$ ).

The cytocompatibility, hemocompatibility, and stability, including long-term storage stability (six months), under different $\mathrm{pH}$ conditions were studied and assessed with surface plasmon resonance, suggesting promising properties of protein functionalized nanoparticles as opposed to plain AuNPs.

Importantly, results from these authors show that unfunctionalized AuNPs induce an $8 \%$ red blood cells lysis, whereas the protein-functionalized particles reached only $2 \%$, and no significant differences were observed in the hemolytic profile of KP-AuNPs, AP-AuNPs, and KP-AP-AuNPs. Overall, the work by Gnanamani and colleagues indicated that keratin alone or in combination with albumin could serve as an effective functional protein for augmenting gold nanoparticles biocompatibility and stability.

Patients affected by type II diabetes mellitus (T2DM) experience compromised parameters of glucose metabolism and removal along with peripheral insulin resistance, which leads to the development of complications such as chronic hyperglycemia, and acute glycemic fluctuations [28]. Theivendren and co-workers recently focused their studies on the use of human hair keratin as carriers of indoloquinoxaline (INDX) derivatives for the treatment of T2DM [29]. This pathogenic condition leads to hyperglycemia and, therefore, more insulin is required to take up glucose into the muscle, adipocytes, and liver. $\mathrm{Nu}$ merous studies have demonstrated that activation of adenosine monophosphate-activated protein kinase (AMPK) and down regulation of protein tyrosine phosphatase 1B (PTP1B) are beneficial for treating T2DM. Therefore, the authors designed and synthesized INDX derivatives incorporated into keratin NPs by the solid dispersion method [30,31].

The entrapment efficiency and loading capacity of INDX into the keratin carrier were 89 and 11.9\%, respectively. Further, the authors demonstrated that INDX@KNPs stimulate glucose metabolism through an AMPK- (insulin independent) and PTP1B (insulin dependent)-mediated signaling pathway, and that the efficiency of glucose metabolism induced by INDX@KNPs in 3T3-L1 adipocytes is significant as compared to antidiabetic drugs such as Metformin and Pioglitazone, overall demonstrating that INDX@KNPs could represent promising antidiabetic systems.

Wound healing has a significant economic and social impact, and accelerating its progression represents a central concern for patients, doctors, and caregivers [32]. The use of biomaterials able to promote cell adhesion and proliferation represents a promising approach to face this issue [33], and among these, keratin is considered a very promising option because of its intrinsic cell growth and proliferation ability, biocompatibility, biodegradability, and natural abundance [34].

In 2019, Hao and coworkers investigated the wound healing ability of recombinant human hair keratin proteins in the form of nanoparticles [35]. The authors studied the use of human type I hair keratin 37 and human type II hair keratin 81, obtained using a bacterial expression system. These keratins were then used to produce the corresponding RKNP37 and RKNP81 nanoparticles via ultrasonic dispersion method. In vitro cell proliferation studies demonstrated that RKNP37 and RKNP81 significantly increased the proliferation of HaCaT cells compared to untreated control, and, among the two, RKNP81 displayed a stronger cell proliferation capacity when the nanoparticle concentration was higher than $0.75 \mathrm{mg} / \mathrm{mL}$. The authors also evaluated the wound-healing efficiency of the RKNPs in vivo, as opposed to untreated control and KNPs made from non-recombinant keratin. Results showed that wounds treated with RKNP37, RKNP81, and KNPs had faster closure compared to the control group after seven days of treatment, and the wound size reduction was 49,56 , and $40 \%$ for the wounds covered by RKNP37, RKNP81, and KNPs, respectively. On day 14, the control group displayed 69\% wound closure, whereas RKNP37, RKNP81, and KNPs showed wound closures of 81,85 , and $74 \%$, respectively (Figure 4). These results indicated that keratin nanoparticles accelerate the wound healing process, and that 
recombinant KNPs have greater wound-healing ability, most probably due to their higher purity, thus suggesting that this feature plays a key role in the wound-healing process.
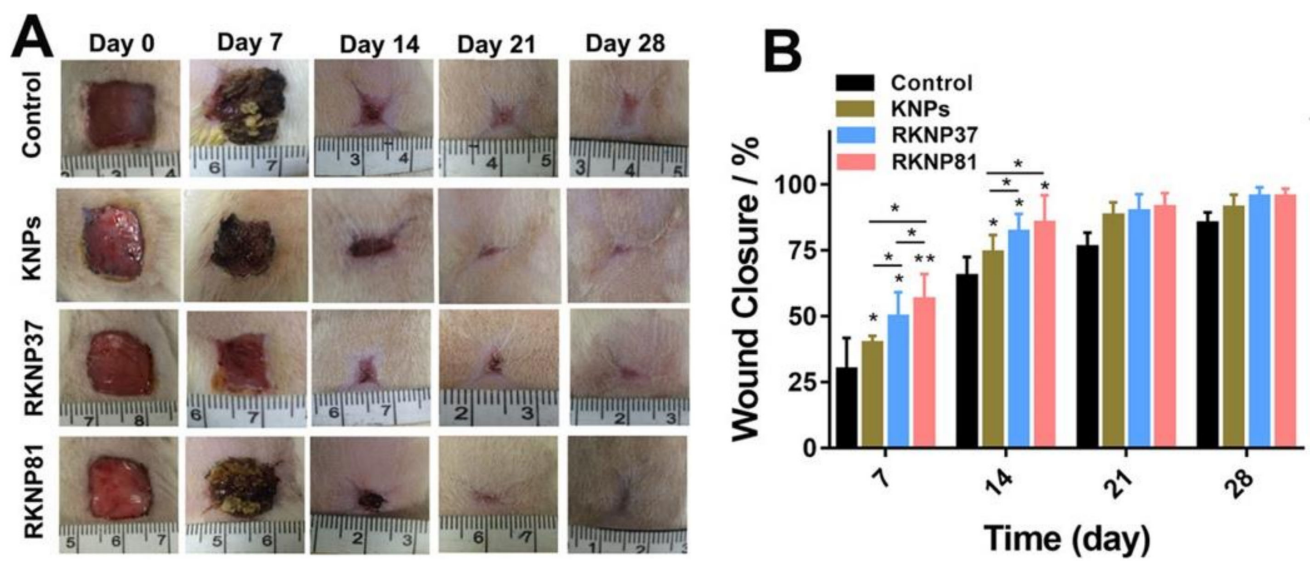

Figure 4. (A) Healing progression of full-thickness cutaneous wounds treated with RKNP37, RKNP81, and KNPs. (B) Rate of wound closure on days $0,7,14,21$, and $28 .{ }^{*} p<0.05,{ }^{* *} p<0.01$ relative to control group. Reprinted with permission from [35]. Copyright 2021 American Chemical Society.

Histopathological analysis showed that more blood vessels were observed in the RKNP37 and RKNP81 groups compared to the control groups after day 14, indicating a greater formation of vascular networks essential for providing the cells with nutrients and oxygen, and for completing the wound-healing process. Overall, the results from Hao and colleagues represent a very interesting opportunity to exploit recombinant keratin to produce wound healing materials.

Bhattacharjee and coworkers reported the use of human hair keratin for the production of nanoparticles incorporating both rutin $(\mathrm{Ru})$ and quercetin $(\mathrm{Qr})$, with the aim of assessing the role of the keratinous carrier on the biodistribution and site-specific action of these two active ingredients [36]. Rutin and quercetin (Figure 5) are natural flavonoids with promising anticancer properties [37]. In particular, quercetin was identified as an inhibitor of the mutant H-Ras P21 protein in colon cancer cell lines and primary colorectal tumors normally found in humans, thus being potentially effective in arresting cancer cell proliferation [38,39].<smiles>CC(C)COCC1CC(Oc2c(-c3ccc(O)c(O)c3)oc3cc(O)cc(O)c3c2=O)C(O)C(O)C1O</smiles>

Figure 5. Chemical structure of rutin and quercetin.

Dual loaded keratin NPs were prepared by solid dispersion method that afforded KNPs of about $50 \mathrm{~nm}$ with an encapsulation efficiency and drug loading capacity of Ru of $91 \%$ and $8.58 \%$, respectively and of Qr of $86.5 \%$ and $9.74 \%$, respectively. The Ru-Qr in vitro release form KNPs was estimated over time, resulting in a sustained behavior within the first observation time $(17.5 \%$ and $21 \%$ within $5 \mathrm{~h}$, respectively), and reaching a higher release extent after $30 \mathrm{~h}$ ( $88 \%$ and $85 \%$, respectively). 
The authors also described an in-silico study that accounted for a strong interaction between Ru-Qr-KNPs and the binding pockets of H-Ras P21 proto-oncogene. Results obtained in silico were further supported by experimental studies on HeLa cells, affording $92 \%$ cell death after $24 \mathrm{~h}$. Overall, the in vitro anticancer activity of Ru-Qr encapsulated KNPs at different concentrations showed that Ru-Qr encapsulated within NPs can reduce the cells viability in a dose-dependent manner.

Mucoadhesion describes the ability of two materials, among which at least one is a biological material, to adhere to each other for a long time by establishing interfacial bonding [40]. Nanotechnology-based drug carriers have been widely exploited for oral and systemic administration of drugs based on their mucoadhesive properties to increase drugs residence time, selectively address the drug to a specific body compartment, reduce the administration frequency, and improve drug bioavailability [41].

On this basis, Wang and coworkers reported the use of human hair keratin as biomaterial for the production of mucoadhesion controlled keratin-based drug delivery systems [42]. The authors described the use of different blends of keratose (KOS) and kerateine (KTN), that were obtained according to different extraction methods, for KNPs production. Indeed, the cysteine sulfur atoms of KTN and KOS were in the form of thiols and sulfonic acids, respectively, which resulted in different mucoadhesive and hydrophilic properties, and diverse solubility, surface charge, and degradation rate. The authors reported the preparation of KNPs with different ratios of KOS to KTN and incorporating amoxicillin (AMO) as a model drug to achieve controlled gastric mucoadhesion and drug release.

Composite keratin nanoparticles with different mass ratios of KTN/KOS, e.g., 100/0, $75 / 25,50 / 50$, and $25 / 75$, were prepared via the ultrasonic dispersion method. The loading capacity of AMO decreased from 15.7 to $8.9 \%$ with an increase in the KOS ratio. A possible explanation of this behavior could be related to the higher ability of KTN to agglomerate and form nanoparticles under acidic conditions as opposed to KOS.

KTN and KOS nanoparticles displayed positive or negative surface charge in a simulated gastric fluid (SGF), respectively, and a gradual decrease in the zeta potential of KNPs was observed with increasing KOS proportion. The release profiles of AMO from KNPs were investigated in SGF, showing a that higher release rate was achieved by increasing KOS ratio. In summary, KTN/KOS KNPs showed good gastric retention capacity that could be adjusted by changing the ratios of KNT to KOS; importantly, in vivo toxicity studies of KNP $(380 \mathrm{mg} / \mathrm{kg})$ indicated no apparent toxicity after oral administration after seven days.

The aim of a second study from the same authors was to prepare keratin nanoparticles as a novel kind of hemostatic agents [43]. Based on the observation, KNPs have a great specific surface area, a better film-forming property, and can supply a higher water uptake, and, thus, keratin nanoparticles should represent more efficient hemostatic materials as compared to keratin powders. Keratins were extracted from human hair by a reduction method, and an ultrasonic solidification process was used for KNPs preparation, by varying both keratin concentration and injection speed.

KNPs size gradually increased both with growing keratin concentrations and increasing the protein solution injection speed. In vivo hemostasis studies were performed on liver puncture and tail amputation in rat models: $25 \mathrm{mg}$ of keratin extracts and $50 \mathrm{mg}$ of KNPs were used for covering the wound areas. Of note, in the liver puncture experiment, approximately $300 \%$ and $400 \%$ reductions in blood loss were observed for the application of keratin extracts and KNPs, respectively (Figure 6A). Overall, the hemostatic time of keratin extracts and KNPs was shorter than control groups, and KNPs showed an improved effect as compared to keratin powder both in liver puncture and tail amputation (Figure 6B). 

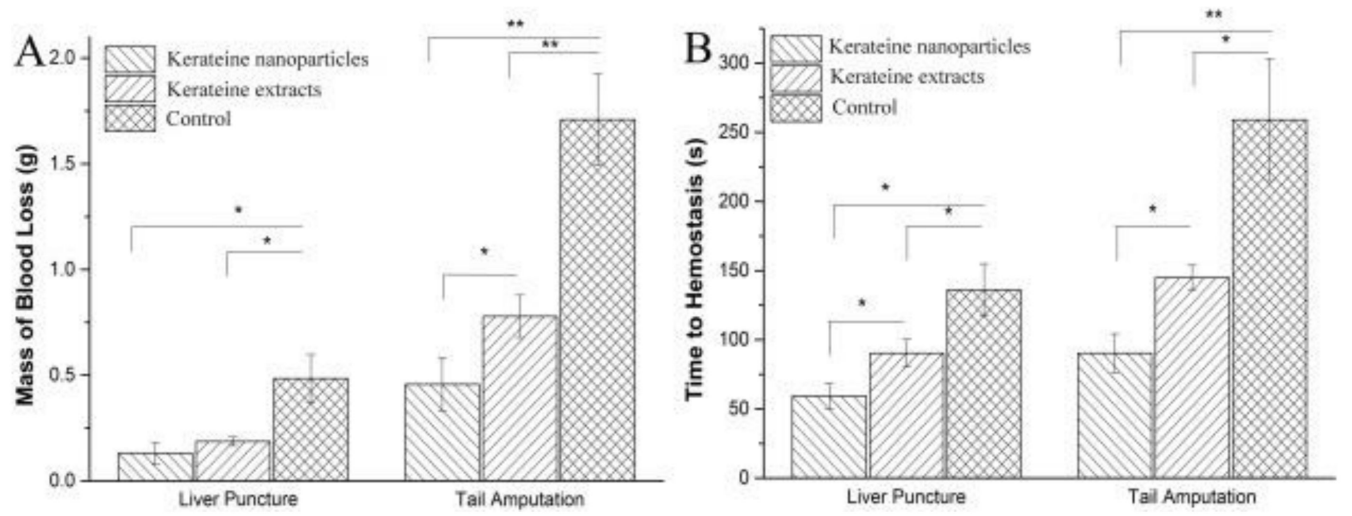

Figure 6. (A) Mass of blood loss and (B) time to hemostasis in rat liver puncture and tail amputation models treated with keratin extracts and KNPs ${ }^{* *} p<0.01$ and ${ }^{*} p<0.05$ compared with the control group, $n=3)$. Reprinted with permission from [43].

Chlorhexidine (CHX) is widely used to treat and prevent skin and mucosal infections; in dentistry, it has been recognized as a gold standard against plaque and gingivitis for three decades [44]. Due to its cationic charge, Shen and coworkers used CHX as a drug model for the preparation of CHX-KNPs (KCNPs) by exploiting the natural electrostatic interaction between the negatively charged protein and the cationic drug by using the drug induced ionic gelation technique as well as with different ratios of keratin and CHX, e.g., $9 / 1,7 / 3$, and $5 / 5$ [16]. For their purpose, the authors extracted keratin from human hair using the reduction strategy, allowing them to isolate a protein characterized by two major clusters of bands: the 25 and $40 \mathrm{kDa}$.

The nanoparticles' stability was evaluated over time, showing that KCNPs at the ratio of $9 / 1$ are stable even when standing for the longest period. Release experiments, performed under different conditions, showed that only the $8 \%$ of $\mathrm{CHX}$ was released within $100 \mathrm{~h}$ in basic environment, probably due to the enhanced negative charges of the KCNPs that tightly adsorb CHX. Conversely, about $39.5 \%$ of $\mathrm{CHX}$ was released within $240 \mathrm{~h}$ at $\mathrm{pH}$ 5. Since an antibacterial material requires low toxicity to normal cells, the cytotoxicity of KCNPs towards fibroblasts was evaluated, showing that, at a lower concentration ( $2.5 \mathrm{mg} / \mathrm{mL}$ of KCNPs, i.e., $0.2 \mathrm{mg} / \mathrm{mL}$ of CHX), the cell viability was reduced to $66 \%$ as compared to the FBS control, indicating that CHX cytotoxicity is enhanced when complexed with keratin. Besides, antibacterial analyses confirmed the effectiveness of KCNPs and their superior activity against Gram-positive microbes as opposed to Gram-negative ones. Despite being promising, these data account for a greater side toxicity of KPNPs, which might reduce their system applicability as antibacterial agents.

\subsubsection{Doxorubicin-Loaded Human Hair Keratin-Based Nanoparticles}

Over the past years, several research groups have focused their attention on the use of human hair keratin to deliver doxorubicin (DOX), intending to exploit both the intrinsic characteristics of this biomaterial (e.g., biodegradability, biocompatibility, and tumor responsiveness) and its high affinity with DOX. The following section will provide a brief overview of the most relevant results and references on this topic.

Tea catechins are a group of polyphenolic compounds extracted from green tea leaves known to possess preventive and therapeutic effects against cancer and many other diseases (Figure 7) [45,46]. 
<smiles>Oc1cc(O)c2c(c1)OC(O)C(c1ccc(O)c(O)c1)C2</smiles>

(+)-Catechin<smiles>O=C(OC1Cc2c(O)cc(O)cc2O[C@H]1c1ccc(O)c(O)c1)c1cc(O)c(O)c(O)c1</smiles>

(-)-Epicatechin gallate<smiles>Oc1cc(O)c2c(c1)O[C@H](c1ccc(O)c(O)c1)C[C@H]2O</smiles>

(-)-Epicatechin

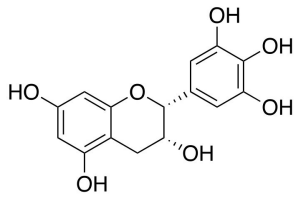

(-)-Epigallocatechin

Figure 7. Chemical structures of (+)-Catechin and four major green tea catechins: (-)-Epicatechin, (-)-Epigallocatechin, (-)-Epicatechin gallate, and (-)-Epigallocatechin gallate (EGCG).

In 2018, $\mathrm{Li}$ and coworker described a straightforward one-pot method to obtain size-controlled and covalently functionalized keratin-catechins nanoparticles, which were further post-loaded with DOX [46]. Through the setup of a systematic methodology, the authors were able to fine tune the ratio of keratin, catechins, and formaldehyde providing KNPs with the most suitable properties for drug delivery. The authors observed that the size of nanoparticles follows a formaldehyde-dependent concentration trend and argued that the morphological evolution of KNPs formation also depends on formaldehyde, which firstly promotes molecular interactions between keratin and catechins, yielding ultra-small nanoparticles of ca. $10 \mathrm{~nm}$ in size; subsequently, these particles act as seeds to continuously grow and finally evolve into spheric and stable nanoparticles.

Among the different batches of KNPs, the authors selected the so-called np4 with a hydrodynamic diameter of $67 \mathrm{~nm}(\mathrm{PDI}=0.121)$ to test their ability to load DOX, and to kill cancer cells in vitro and in vivo. Their results confirmed that np4 effectively upload DOX, while release studies performed in the presence of GSH and trypsin confirmed that nanoparticles quickly disassembled, providing a nearly complete DOX release (ca. $75 \%$ ) within six hours. Given the recognized anticancer capability of catechins, a comparative inhibitory study of free DOX and DOX loaded onto np4 (DOX/np4) was performed on colon cancer cell lines HT-29. The resulting $\mathrm{IC}_{50}$ values were $0.66 \mathrm{mg} / \mathrm{mL}$ for DOX $/ \mathrm{np} 4$ and $0.86 \mathrm{mg} / \mathrm{mL}$ for free DOX, indicating a possible synergistic/additive action of polyphenols to the anticancer effect.

In vivo anticancer activities of DOX/np4 and np4 were performed and compared with pure catechins and free drug on HT-29 xenografted athymic nude mice models, using different administration routes. Results indicated that intraperitoneal (i.p.) administration of pure catechins and np4 gives an $18.8 \%$ and $63.3 \%$ tumor growth inhibition rate, respectively. The tumor growth inhibition rate of intravenously injected (i.v.) free DOX and DOX/np4 was 47.5 and $78.3 \%$, respectively. Of note, the i.p. administration of pure $\mathrm{np} 4$ shows a significantly higher anticancer effect than i.p. administration of equivalent pure catechins, and higher anticancer effects than i.v. injection of free DOX, indicating that the molecular assembly of catechins and keratins into nanoparticles greatly increases the bioavailability and efficacy of tea polyphenols.

MSNs@PDA@keratin nanoparticles from Yuan and colleagues, discussed in the previous section, were further loaded with DOX, displaying a loading content of $24.5 \%$ and an encapsulating efficiency of 71.3\%. MSNs-DOX@PDA@keratin showed good pH and GSH responsiveness, as well as selective toxicity against A549 tumor cells as opposed to normal L929 cells (Figure 8), thus representing a promising approach to promote MSN-based drug delivery [26]. 

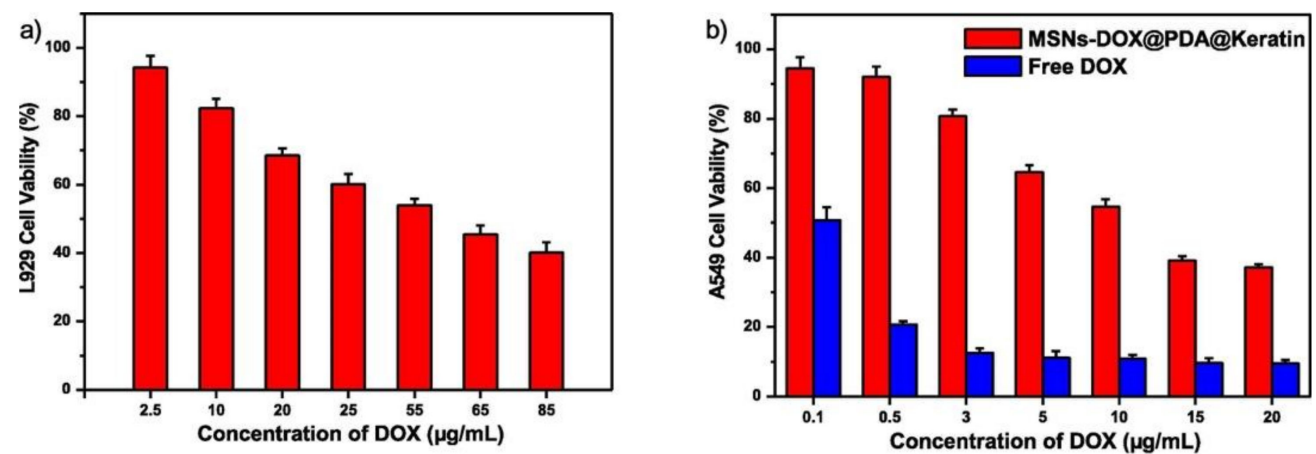

Figure 8. Toxicity of MSNs-DOX@PDA@keratin on L929 cells (a); toxicity of MSNs-DOX@PDA@ keratin and free DOX against A549 cells (b).

In a previous paper, the same authors further deepened the production of DOXloaded human hair KPNs with high GSH and $\mathrm{pH}$ responsiveness [47]. As opposed to other literature reports, this work describes the preparation of KNPs from reduced human hair keratin in the presence of $\mathrm{H}_{2} \mathrm{O}_{2}$. As claimed, this procedure allows for nanoparticles' stabilization by a "green" self-crosslinking approach that encompasses the oxidation of thiols to disulfide bridges. Post-loading with DOX provided KNPs of around $130 \mathrm{~nm}$ with a $11.5 \%$ loading content and an encapsulation efficiency of $49.4 \%$. The authors further demonstrated that, under increasing GSH concentrations, the zeta potential of KNPs changed from negative $(-9.5 \mathrm{mV})$ to positive $(4.86$ and $5.1 \mathrm{mV})$, and their size significantly increased, indicating a marked disassembly. In vitro cytotoxicity studies revealed that KNPs loaded with DOX reduced tumor cells viability (A549) in the low micromolar range, despite being less potent than free DOX.

On the same topic, Shen and co-workers reported the preparation of keratin-PDA conjugates for the production of biodegradable nanoparticles carrying DOX [48] by exploiting the ability of PDA to polymerize under mild conditions. For their work, the authors extracted keratin from hair in the form S-carboxymethyl keratin that was subsequently reacted with dopamine under $\mathrm{EDC} \cdot \mathrm{HCl} / \mathrm{NHS}$ standard conditions. Afterward, the dopamine pendant of the synthesized conjugate was self-polymerized under mild alkaline conditions to afford blank keratin/PDA nanoparticles, which were further loaded with DOX through electrostatic interaction and hydrogen bonding. DOX-loaded nanoparticles displayed good $\mathrm{pH}$ and GSH responsiveness and a higher inhibitory effect on tumor cells than normal cells.

Xiao and collaborators described the use of human hair keratin for the production of $\mathrm{pH}$-sensitive DOX-loaded nanoparticles (KDNPs) able to release the drug at the tumor site [19]. To this purpose, S-carboxymethyl keratin was extracted from human hair and modified with iodoacetic acid; afterwards, keratin-DOX conjugate was prepared into nanoparticles by desolvation using genipin as a green cross linker [49].

Release of DOX from KNPs was carried out at $\mathrm{pH} 7.4$ and $\mathrm{pH} 5.0$ to simulate a normal physiological condition and the acidic tumor microenvironment, respectively, showing that the cumulative release of DOX over a period of $270 \mathrm{~h}$ was $5 \%$ and $78 \%$ at $\mathrm{pH} 7.4$ and at $\mathrm{pH}$ 5.0, respectively. The authors claim that the $\mathrm{pH}$-sensitive release characteristics of KDNPs were mainly ascribable to the break of the hydrazone bonds between keratin and DOX at $\mathrm{pH}$ 5.0, resulting in an enhanced release. In vitro cytotoxicity studies on A549 cells showed that the $\mathrm{IC}_{50}$ of free DOX $(0.8 \mu \mathrm{g} / \mathrm{mL})$ was considerably lower than that of KDNPs $(5.0 \mu \mathrm{g} / \mathrm{mL})$, probably due to the faster uptake of free DOX into 2D cells system. Indeed, in vivo evaluation showed that animals in the KDNPs group had higher body weight, indicating lower toxicity, whereas tumor volume and weight for the free DOX and control groups were both larger and higher than those of the KDNPs group, demonstrating a better in vivo performance of KDNPs as opposed to free DOX both in terms of systemic toxicity and antitumor efficacy. 
Keratin-hyaluronic acid nanogels were reported by $\mathrm{Li}$ and collaborators as drug carriers with high a DOX content and targeting ability, thanks to the presence of hyaluronic acid [50]. The CD44-targeted nanogels displayed greater DOX tumor uptake as opposed to the free drug and high tumor microenvironment responsiveness. Importantly, the authors demonstrated that their nanogels were able to improve intracellular NO levels and enhance the anticancer efficacy of DOX in vitro and in vivo, while having lower side effects compared to free DOX.

Yuan and collaborators described keratin/DOX complex nanoparticles obtained by ionic complexation, hydrogen bonding, and hydrophobic interactions between the protein and DOX [51]. These particles exhibited excellent $\mathrm{pH} / \mathrm{GSH} /$ enzyme triple stimuliresponsiveness, resulting in efficient drug release under tumor microenvironment mimicked conditions. In vivo cytotoxicity and hemolysis analyses showed that KDNPs exhibited excellent biocompatibility as well as good blood compatibility. Antitumor efficacy in tumor-bearing mice indicated that KDNPs had a strong antitumor effect, similar to that exerted by free DOX.

Very recently, Shen and colleagues described the production of nanoparticles made of a keratin-tannic acid complex loaded with DOX [52]. Tannic acid is a natural polyphenol generally used as a non-toxic cross-linker for proteins. These nanoparticles had an average hydrodynamic diameter of $240 \mathrm{~nm}$ and exhibited a dual $\mathrm{pH}$ and GSH responsiveness, being capable of releasing DOX at the tumor site. In vitro analyses demonstrated that DOX-loaded nanoparticles were effectively endocytosed by tumor cells and had a higher inhibitory effect on tumor cells as opposed normal cells.

Similarly, Lin et al. studied the use of human hair keratin for the preparation of keratin/DOX nanoparticles with the desolvation/cross linking method, obtaining particles of $\sim 182 \mathrm{~nm}$ with an encapsulation efficiency of $47 \%$, and a drug loading rate of $14 \%[53,54]$. Moreover, the reported nanoparticles exhibited good $\mathrm{pH} / \mathrm{GSH}$ responsiveness as well as charge reversibility under tumor microenvironment conditions, e.g., low $\mathrm{pH}$ and a high GSH level, which favored their internalization into A549 tumor cells. Keratin/DOX nanoparticles showed low toxicity towards normal cells and a low hemolysis ratio; conversely, they efficiently inhibited tumor cells growth in vitro.

\subsection{Wool Keratin-Based Nanoparticles}

About two million tons of wool are produced yearly, Australia being the major contributor (over 25\%), and wool wastes from textile industries have gained a growing relevance as a renewable source of keratin. Indeed, wool consists of up to $95 \%$ of keratin that can be obtained from the hairy part of the hide of sheep, goats, pigs, rabbits, and camelids [8]. To reduce the environmental impact of textile waste, several keratin extraction procedures have been applied, and the extracted protein has found wide application in the drug delivery field. It is worth noticing that wool-derived keratin seems highly compatible with human biological systems, possessing the same key cell-binding motifs of human keratin that are crucial to support and promote cellular adhesion [55].

In 2013, Cilurzo et al. demonstrated, for the first time, the feasibility of producing biocompatible keratin-based microparticles starting from wool wastes, and further confirmed particles' safety on human monocytic cell line [56]. In detail, the authors prepared an aqueous solution of regenerated keratin (RK) with a final concentration of $4.5 \% w / w$, via sulfitolysis procedure. The FTIR analysis revealed that RK was mainly organized in the disordered $\alpha$-helix structure, thus resulting in a remarkable water-solubility. After acidic treatment ( $\mathrm{pH}$ 3.5) followed by washing with water, the RK solution was spray-dried, providing microparticles with a mean diameter of $6 \mu \mathrm{m}$, a narrow size distribution, and an irregular and smooth surface. Overall, the in vitro biocompatibility assays, performed on human monocytic cell lines at increasing microparticle concentrations (from $1 \mu \mathrm{g} / \mathrm{mL}$ up to $1000 \mu \mathrm{g} / \mathrm{mL}$ for 24 or $72 \mathrm{~h}$ ), confirmed the particles' safety. Based on this evidence, various straightforward and water-based procedures have been envisioned which are aimed at obtaining KPNs with tunable morphological, physical, and chemical properties. 
As previously mentioned, the sulphitolysis procedure allows for the obtainment of water-soluble and full-length keratin, that, most importantly, preserves the naïve protein primary and secondary structure. In the past few years, several kinds of antitumoral therapeutics (chlorin e6, paclitaxel, doxorubicin, and 9(R)-9-hydroxystearic acid) have been loaded into keratin nanocarriers. In this regard, our research group described, for the first time, the covalent attachment of the photosensitizer chlorin e6 (ce6) on the keratin backbone via EDCI/NHS coupling, followed by nanoparticle formation, e.g., KNPs@Ce6, by self-assembly and desolvation techniques [57]. Both the self-assembly and desolvation methods provided stable nanoparticles with comparable hydrodynamic diameters (148 vs. $147 \mathrm{~nm}$ ) and Ce6 loading ratios (23 vs. $45 \%$ ), with a monodisperse distribution (PDI: 0.17 vs. 0.13$)$, a negative zeta potential ( -53 vs. $-68 \mathrm{mV}$ ), and with a final yield of $24 \%$ and $30 \%$, respectively. The loading of Ce6 on KNPs@Ce6 suspensions $(0.1 \mathrm{mg} / \mathrm{mL})$ ranged between 35 and $38 \mu \mathrm{g} / \mathrm{mg}$ of keratin, and was confirmed by UV-vis spectroscopy, displaying a broadened Soret band $(400 \mathrm{~nm})$ and a bathochromic shift from $650 \mathrm{~nm}$ to $665 \mathrm{~nm}$ of the Q-band. After a $24 \mathrm{~h}$ incubation period at different concentrations (e.g., 0.5, 2.5, $5.0 \mu \mathrm{g} / \mathrm{mL}$ ), KNPs@Ce6 showed a superior internalization compared to free Ce6 on osteosarcoma (U2OS) and glioblastoma (U87) cell lines, and upon light irradiation they produced a large amount of reactive oxygen species (ROS), triggering cell death in a concentration and irradiation-time dependent manner. We further exploited KNPs for delivering paclitaxel (PTX), an anticancer agent widely used in breast and ovarian cancers. KER-NPs-PTX were tested against human breast cancer MCF-7 and MDA MB 231 cell lines in two-dimensional (2D) cultures and in a perfused three-dimensional (3D) model [58]. Primarily, keratin showed an extraordinary PTX loading ratio up to sevenfold higher as compared to those of albumin, e.g., $43 \%$ vs. $6.5 \%(w / w)$. Moreover, KER-NPs-PTX exerted effective anticancer activities on both $2 \mathrm{D}$ and $3 \mathrm{D}$ models, leading to a significant increase in the expression of the proapoptotic $B A X$ gene and cleaved caspase 3 (CC3) protein, and an increment in apoptotic cell percentages, following $24 \mathrm{~h}$ treatment. Although monotherapy remains a widely used approach for cancer treatment, its application is strictly limited by severe toxicity, as well as the development of resistance and recurrence phenomena. Therefore, a bimodal therapy combining photo- and chemotherapy could represent an encouraging strategy to overcome these limitations by reducing the effective drug dose and synergistically targeting different pathways.

In this regard, we employed keratin for preparing nanoparticles co-loaded with PTX and Ce6 via drug-induced aggregation and desolvation procedures (PTX-Ce6@kerag and PTX-Ce6@ $@ k_{\mathrm{ds}}$ ) as an innovative approach for the pharmacological treatment of osteosarcoma (OS) [18]. Both methods provided stable nanoparticles with a negative zeta potential (around $-46 \mathrm{mV}$ ). As expected, PTX-Ce6@ker $\mathrm{ds}_{\mathrm{ss}}$ resulted as smaller and more mono-disperse than PTX-Ce6@ker ${ }_{a g}$ (hydrodynamic diameter 120 vs. $150 \mathrm{~nm}$, and PDI 0.067 vs. 0.22 , respectively), most probably due to the cross linking mediated by glutaraldehyde. In vitro cytotoxicity assays performed on three osteosarcoma cell lines (MG63, SaOS-2, U-2 OS) indicated that PTX-Ce6@ker ${ }_{\text {ag }}$ displayed a pharmacokinetic profile similar to free PTX, resulting in a significant decrease in cell viability. On the other hand, PTX-Ce6@ker $\mathrm{ds}_{\mathrm{s}}$ achieved the same cytotoxic effect at higher concentrations; indeed, the crosslinking process may affect the release of PTX, strongly reducing its efficacy. Therefore, PTX-Ce6@ker ${ }_{\mathrm{ag}}$ was selected as the nanoformulation more suitable for further in vitro investigations both in 2D and 3D OS models. Remarkably, cells loaded with PTX-Ce6@ker ag, at a final Ce6 and PTX concentration of $3.35 \mathrm{mM}$ and $6.52 \mathrm{mM}$, respectively, upon light irradiation, showed a dramatic decrease in cell viability, as well as in chemoresistant SaOS-2 cells and in 3D OS models, thus accounting for an additive action of chemotherapy and photoactivation (Figure 9). 


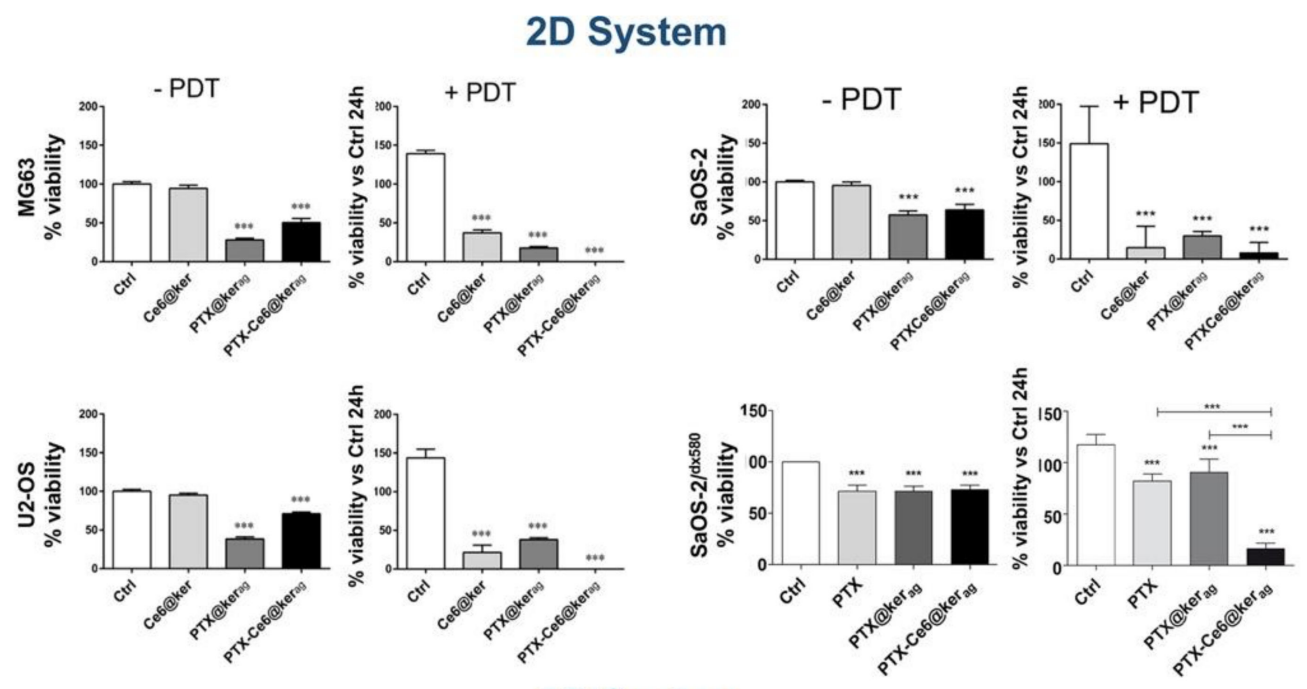

3D System

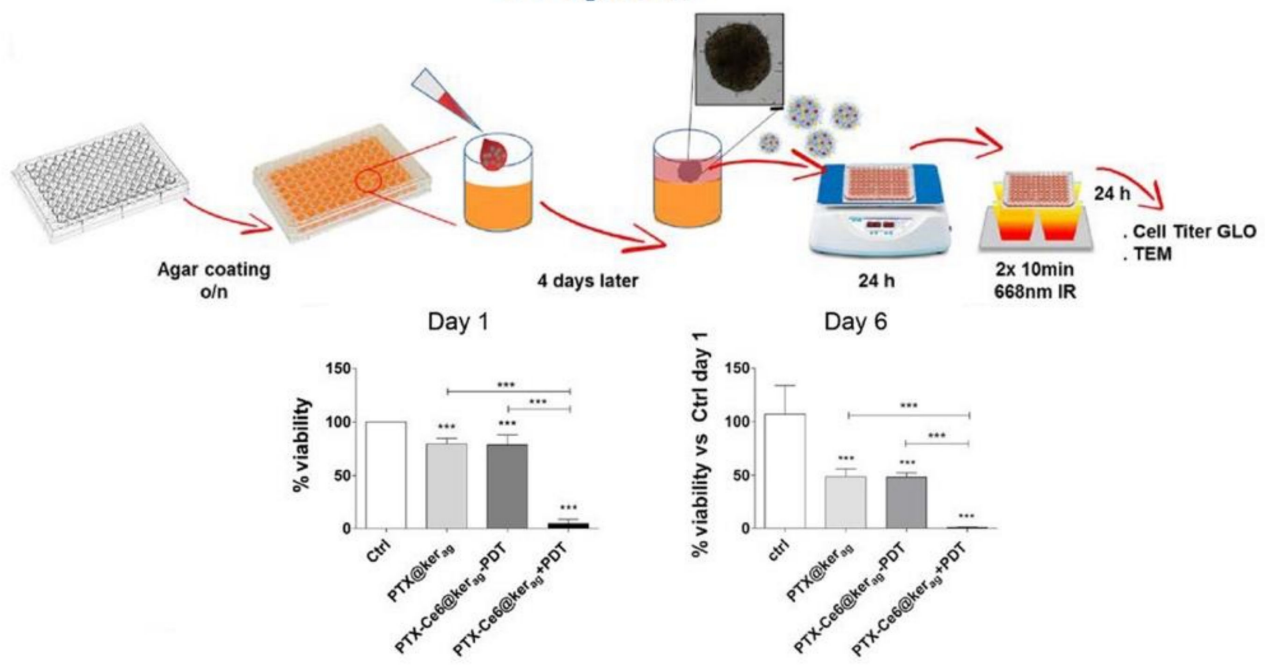

Figure 9. Impact of PTX-Ce6@kerag on 2D and 3D OS tumor model. Reprinted under Creative Common CC BY license from [18]. ${ }^{* *} p<0.001$.

9(R)-9-hydroxystearic acid (9HSA) is an endogenous lipid, known to inhibit histone deacetylase (HDAC1) at micromolar concentration. 9-HSA induces a cell cycle arrest in the $\mathrm{G} 0 / \mathrm{G} 1$ phase and activates the $\mathrm{p} 21^{\mathrm{WAF} 1}$ gene, therefore representing a promising and non-toxic option for cancer treatment. However, 9-HSA is poorly water-soluble and its encapsulation within a nanocarrier could improve its pharmacokinetic and pharmacodynamic profile. To this end, our group exploited the high affinity of keratin towards hydrophobic molecules to produce 9-HSA KNPs (9R@ker) through an in-water drug-induced aggregation method. Optimization studies allowed for the establishment of the optimal parameters for obtaining stable and highly reproducible NPs with an average diameter of $162 \mathrm{~nm}$ (PDI < 0.2), a negative zeta-potential of $-43 \mathrm{mV}$, and a drug loading of $10 \mathrm{wt} \% / \mathrm{ker}_{\mathrm{wt}}$, reaching a higher $9 \mathrm{R}$ loading ratio with respect to those obtained with hydroxyapatite, e.g., 10 vs. $8.6 \%$. Therefore, $9 \mathrm{R} @$ ker nanoparticles were investigated for in vitro antitumor activity compared with free 9R and 9R albumin-loaded NPs towards three human colon cancer cell lines, i.e., HT29, Caco-2, and HCT116. In vitro antiproliferative data indicated that 9R@ker induced a higher antiproliferative effect than the free drug, especially on HT29 cells ( 49 vs. $26 \%$ ). Noteworthy, is that after incubation with nanoparticles, HT29 cells showed an increased cell membrane fluidity, and a greater intracellular ROS production, leading to cell death due to the unexpected $S$ phase cell cycle arrest (25\% increase as compared to the control) [59]. 
Similarly, for the treatment of breast cancer, we fabricated DOX-loaded KNPs through ionic gelation and aggregation techniques (DOX-KNPs_IG and DOX-KNPs_Agg, respectively). DOX-KNPs_IG allowed a higher drug loading (up to $30 \mathrm{wt} \%$ ) and a pH-responsive release; most interestingly, they showed a similar antiproliferative activity compared to free DOX, both against MCF-7 and MDA-MB-231 cells, whereas DOX-KNPs_Agg induced lower antitumoral activity on both cell lines [60].

In 2012, keratin has been grafted with polyethylene glycol in different ratios to obtain three types of keratin-g-PEG copolymers. Indeed, according to the keratin content, ranging from 14 to $48 \% w / w$, the concentrations of the graft copolymers were $0.21,0.27$, and 0.71 $\mathrm{mg} / \mathrm{mL}$ (keratin ${ }_{0.25}$-g-PEG, keratin 0.41 -g-PEG, and keratin ${ }_{0.97}$-g-PEG, respectively). Preliminary in vitro experiments demonstrated that blank graft copolymers have no cytotoxicity to the MCF-7 cell line, and the relative cell viability remained above $80 \%$ under different concentrations of keratin-g-PEG after $24 \mathrm{~h}$ incubation. All obtained copolymers were able to self-assemble into nanoparticles in aqueous medium and to load a significative content of DOX (up to $18.1 \mathrm{wt} \%$ in keratin 0.25 -g-PEG). To increase nanoformulations stability for in vivo administration, KNPs were crosslinked with DMSO (thiol oxidation into disulfide bonds). Release experiments revealed that keratin ${ }_{0.25}$-g-PEG nanoparticles showed the most favorable release profile under higher GSH levels $(10 \mathrm{mM})$, releasing about $50 \%$ of loaded DOX within $12 \mathrm{~h}$ [61]. On this basis, Curcio et al. grafted polyethylene glycol-40 stearate with keratin to produce redox-responsive polymersomes with a mean diameter of $134 \mathrm{~nm}$ and PDI lower than 0.25 , and post-loaded with hydrophilic methotrexate (MTX@KerPs) and hydrophobic curcumin (CUR@KerPs) (entrapment efficiencies of 80\% and $85 \%$, respectively). MTX is a folate antagonist, interfering with DNA and protein synthesis, and cell replication; instead, CUR is a potent antioxidant and anti-inflammatory agent, suppressing tumor cells proliferation [62]. As shown in Figure 10a, nanocarriers biocompatibility was investigated through MTT assay on Balb3T3 cells, revealing that cell viability was not compromised at any tested concentration (from 1.65 to $33 \mu \mathrm{g} / \mathrm{mL}$ ). The two different polymersomes were efficiently internalized via endocytosis by HeLa and CHO-K1 cells, exhibiting GSH-triggered release profiles (>80\% within nine hours), and thus inhibited HeLa and CHO-K1 cancer cells proliferation (Figure 10b,c).
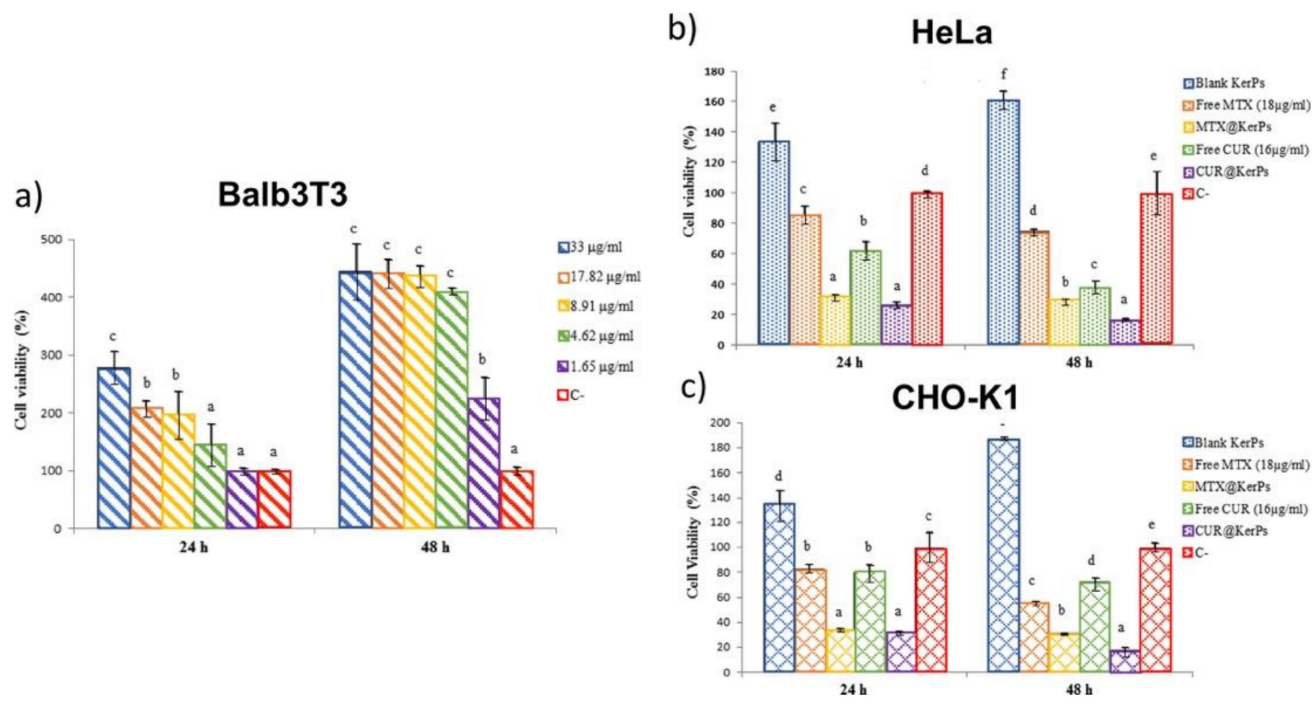

Figure 10. (a) Balb3T3 cell viability after incubation with blank KNPs at different concentrations for 24 or $48 \mathrm{~h}$. (b) HeLa and (c) CHO-K1 cells viability when exposed to blank and drug-loaded KNPs $(33 \mu \mathrm{g} / \mathrm{mL})$ after 24 and $48 \mathrm{~h}$. Adapted with permission from [62]. Copyright 2021 American Chemical Society. 
Novel keratin nano- and micro-particles (size ranging from 200 to $800 \mathrm{~nm}$ ) were prepared from a blend of protein and poly(vinylalcohol) (1:2), followed by a simple and efficient loading of different kinds of drugs and nanotherapeutics: eosin Y, carmine red, methylene blue, curcumin, FITC-albumin, and gold nanoparticles (AuNPs, $5 \mathrm{wt} \%$ ). In detail, the positive charged methylene blue and AuNPs attained the highest encapsulation efficiency ( $88 \%$ and $93 \%$, respectively), confirming their remarkable affinity for keratin. It is worth mentioning that all these nanoformulations proved the establishment of a strong interaction with mucin, probably due to cysteine residues that confer to keratin tunable mucoadhesive properties. In fact, the loading of neutral hydrophobic entities strongly enhanced the interaction between keratin particles and mucosal tissues as compared to charged molecules [63].

Notably, keratin scaffold has found pioneering application as an electrochemical biosensor for extremely stable $(92.9 \%$ activity after 35 days), repeatable $(2.16 \%)$, and reproducible $(3.75 \%)$ dsDNA absorption. In detail, Saçak and collaborators extracted keratin from wool waste, through chemical reduction using a $2.0 \mathrm{M}$ urea or $1.5 \mathrm{M}$ thiourea solution under a nitrogen atmosphere. After the addition of NaHS, KerSH nanoparticles were prepared and subsequently mixed with $\mathrm{Pd}^{2+}$ ions at ambient temperature for $120 \mathrm{~min}$, providing an adsorbed $\mathrm{Pd}^{2+}$ content of about $63.7 \mathrm{mg} \mathrm{Pd} / 1 \mathrm{~g}$ KerSH [64]. Finally, the Ker-SH-Pd ${ }^{2+}$ dispersion was drop-casted onto a glassy carbon electrode (GCE) surface, obtaining GCE/KerSH-PdNPs electrode as an efficient and stable platform for dsDNA immobilization via passive adsorption.

In conclusion, keratin nanoparticle composites have demonstrated an impressive efficacy in the encapsulation and delivery of different therapeutic agents. For instance, the conjugation of Pluronic and wool-extracted keratin allowed for the obtainment of a thermosensitive copolymer, capable of encapsulating curcumin up to $7.4 \%$ [20]. These nanoparticles showed a dual redox and temperature-triggered release, a good biocompatibility $(80 \%)$ even at high concentrations $(\leq 1 \mathrm{mg} / \mathrm{mL})$, and an excellent cellular internalization. Recently, Guglielmelli et al. developed an innovative nanosystem, keratin-coated gold nanoparticles (Ker-AuNPs), as promising agents for plasmonic photothermal (PPT) cancer therapy. Ker-AuNPs were investigated in terms of physical-chemical properties, morphology, and photothermal features, revealing a mean hydrodynamic diameter of $32 \mathrm{~nm}$ and a $\zeta$-potential of $-18 \mathrm{mV}$, a good photothermal conversion efficiency and high thermal stability. Preliminary in vitro experiments performed on a human glioblastoma cell line (U87-MG) further confirmed the efficient cellular internalization via an endocytosisbased uptake pathway, an excellent biocompatibility for concentrations up to $50 \mu \mathrm{M}$, and localized photothermal heating capabilities, leading to a reduction in the cell viability of approximately $30 \%$ [65].

\subsection{Chicken Feathers Keratin-Based Nanoparticles}

Chicken feathers represent the major processed waste product from the poultry industry with around six billion tons of feathers produced annually. A detailed chemical characterization of chicken feathers has been conducted by Tesfaye et al., aimed at ascertaining the possible valorization strategies of these waste products [66]. The proximate analysis indicated the following composition: crude lipid $(0.83 \%)$, crude fiber $(2.15 \%)$, crude protein $(82.36 \%)$, ash $(1.49 \%)$, nitrogen free extract $(1.02 \%)$, and moisture content $(12.33 \%)$, whereas the ultimate analysis showed: carbon $(64.47 \%)$, nitrogen $(10.41 \%)$, oxygen $(22.34 \%)$, and sulfur (2.64\%). Thanks to keratin's durability and self-extinguishing properties, chicken feathers represent a valuable raw material in several applications, spanning from textile, plastic, cosmetics, pharmaceuticals, biomedical, and bioenergy industries (Figure 11). Furthermore, the keratin fibers could be used as moisture adsorbent, preventing skin from rashes and infections, and as bio-sorbents for treating waste water [67].

Feather KNPs have been obtained through a plethora of processes, showing tunable and different properties, and making them suitable systems for tissue engineering, wound dressing, and drug carriers. 
Pedram Rad et al. obtained a keratin nano-powder by electro-spraying the trifluoroacetic acid solution of recovered feathers protein. This procedure allowed to obtain nanoparticles with tunable diameters, depending on different parameters. The authors observed that the particle size follows a keratin-dependent concentration trend, yielding smaller KNPs at lower polymer concentration (from 24 to $53 \mathrm{~nm}$ ), as well as increasing the voltage and the nozzle-collector distance, while a higher injection rate led to bigger KNPs. The optimization study allowed for the establishment of the following parameters for obtaining more stable KNPs with an average diameter of $53 \mathrm{~nm}$ : keratin concentration $=0.2 \%$ $(w / v)$, voltage $=15 \mathrm{kV}$, nozzle-collector distance $=15 \mathrm{~cm}$, feed rate $=0.047 \mathrm{~mL} / \mathrm{h} \mathrm{[68]}$.

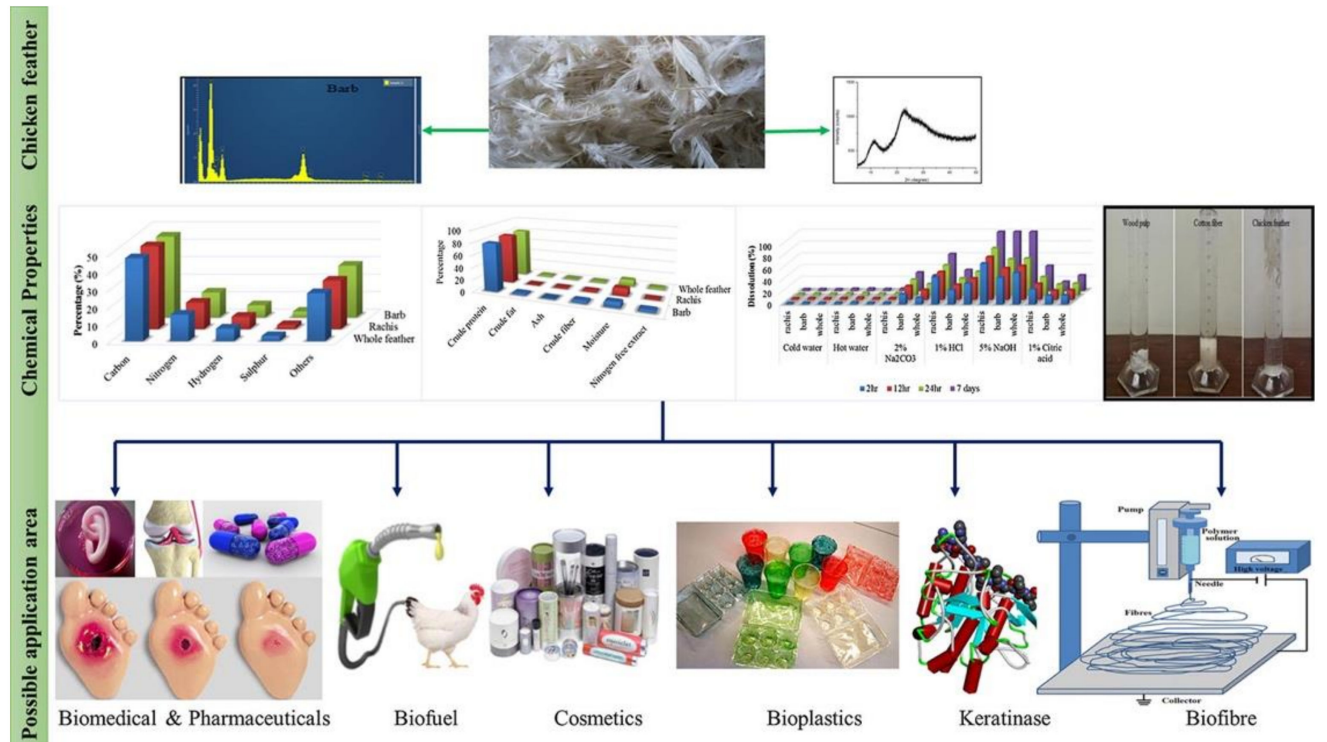

Figure 11. Possible valorization route of waste chicken feather based on chemical properties [66].

Chicken feather KNPs displayed extraordinary biocompatibility in vitro, as demonstrated by Yang and collaborators on fibroblasts, showing improved cells attachment and proliferation [69]. As reported, fibroblasts incubated with a medium containing KNPs showed a gradual and continued proliferation for five days, while cells in KNPs-free medium reached a maximum population at days two and three, followed by a steady decrease. These KNPs, prepared by phase separation and ultrasonication methods, showed an average diameter around $70 \mathrm{~nm}$, and, after injection into mice, were found prevalently in kidneys, where $18 \%$ of cells were penetrated by nanoparticles.

In 2013, Saravan et al. developed a biodegradable and biocompatible keratin/chitosanbased scaffold for bone tissue engineering applications. In detail, spherical keratin nanoparticles (nKer) with a mean diameter of $150 \mathrm{~nm}$ were firstly prepared by the desolvation technique, and then incorporated into a chitosan matrix (CS/nKer). CS/nKer showed a pore size ranging from 17 to $30 \mu \mathrm{m}$, which decreases with increasing nKer content; the addition of keratin nanoparticles to the chitosan scaffold produced a slower degradation of the matrix, making it less accessible to lysozyme, despite the fact that no alteration of the swelling behavior was observed. Remarkably, CS/nKer scaffolds exhibited no significant cytotoxicity towards human osteoblastic cells (MG-63), and the addition of nKer significantly improved proteins absorption on the matrix, resulting in a porous architecture that allowed cells and nutrients penetration and tissue ingrowth [70]. Furthermore, keratinbased carriers displayed other promising biological activities, including hemostatic [71], antioxidant, and anticancer efficacies [72]. 
Liu and collaborators designed and prepared reduction/pH dual-responsive keratinbased nanoparticles as a delivery system of DOX. In detail, DOX was covalently conjugated onto pegylated keratin through an acid-sensible hydrazone moiety or a reductive cleavable linker, allowing the tumor microenvironment-triggered drug release [73,74]. Notably, in vitro release studies demonstrated a sustained and cumulative prodrug leakage up to $43 \%$ within $107 \mathrm{~h}$ in an acidic/reductive environment, while a negligible amount of free DOX was released under physiological conditions. After longer incubation time, prodrugnanoparticles demonstrated a similar or enhanced antitumor efficacy compared to free DOX in HepG2 human liver and MCF-7 breast cancer cells, probably due to the long-term release in tumor intracellular microenvironment.

Recently, keratin has been also investigated as a platform template for both MRI and therapeutic application [72]. Firstly, metal ions (e.g., $\mathrm{Mn}^{2+}$ and $\mathrm{Gd}^{3+}$ ) were sequenced onto protein's backbone by exploiting interaction with thiol and carboxyl moieties. Then, a simple and straightforward mixing procedure provided monodisperse metal oxide nanoparticles, MnNPs@Keratin, and GdNPs@Keratin with an average size of $\sim 5 \mathrm{~nm}$ and $\sim 8 \mathrm{~nm}$ by TEM observation and a hydrodynamic diameter of $\sim 12 \mathrm{~nm}$ and $\sim 25 \mathrm{~nm}$ by DLS analysis. The successful loading of metal ions was confirmed through inductively coupled plasma atomic emission spectrometry (ICP-AES), indicating that the Mn element content in MnNPs@Keratin was 1.3\%, and the Gd in GdNPs@Keratin was 3.8\%. The T1 relaxivity ( $r 1$ value) of MnNPs@Keratin and GdNPs@Keratin reached up to $6.8 \mathrm{mM}^{-1} \mathrm{~s}^{-1}$ and $7.8 \mathrm{mM}^{-1} \mathrm{~s}^{-1}$, respectively, demonstrating concentration-dependent MRI performances. It is worth noting that the T1-weighted relaxivity of MnNPs@Keratin dramatically increased under acid and reducing conditions, due to the release of $\mathrm{Mn}^{2+}$ after the reaction between $\mathrm{MnO}_{2}$ and acids or GSH.

Notably, at concentrations below $250 \mu \mathrm{g} \mathrm{mL}{ }^{-1}$, MnNPs@Keratin displayed nearly $100 \%$ viability in breast cancer $4 \mathrm{~T} 1$ cells and a hemolysis percentage of $1.16 \%$, while GdNPs@Keratin exhibited above $80 \%$ viability at a concentration of $1000 \mu \mathrm{g} \mathrm{mL} \mathrm{m}^{-1}$ and a hemolysis percentage of less than $5 \%$ at $250 \mu \mathrm{g} \mathrm{mL}^{-1}$, thus demonstrating low cytotoxicity and a negligible hemolytic effect of both formulations.

The in vivo biodistribution of nanoparticles was investigated by measurement of the $\mathrm{Mn}$ and $\mathrm{Gd}$ content in the main organs of mice, indicating that, at seven days post-injection, most of the elements were mainly found in the liver, and almost all of the nanoparticles were gradually excreted at $15^{\circ}$ day. The in vivo MR imaging on $4 \mathrm{~T} 1$ tumor-bearing mice revealed an impressive MRI performance, and MnNPs@Keratin showed a maximum T1-weighted after $2 \mathrm{~h}$ of administration, thus offering a suitable time window for the observation via the MR scan.

Based on these promising data, the authors loaded DOX into the metallic oxide nanoparticles by a simple and straightforward mixing procedure, showing excellent drug loading efficiency and capacity (86.8 and 8.7\% for MnNPs@Keratin, and 90 and 9\% for GdNPs@Keratin, respectively). In vitro and in vivo studies on 4T1 breast cancer cells confirmed the nanoparticles' remarkable MRI performance, a $\mathrm{pH}$ and redox-dual responsive DOX release profile, and a significative reduction in tumor growth, thus making these nanoparticles promising candidates for theranostic applications (Figure 12). 
A

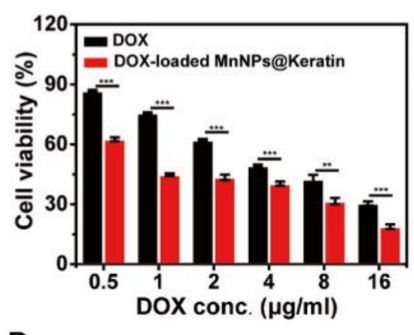

D

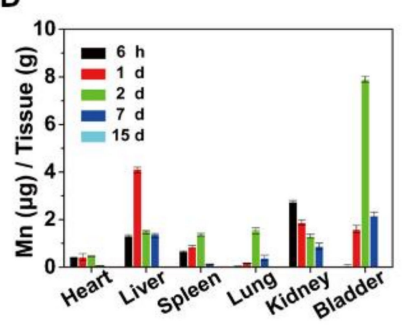

B

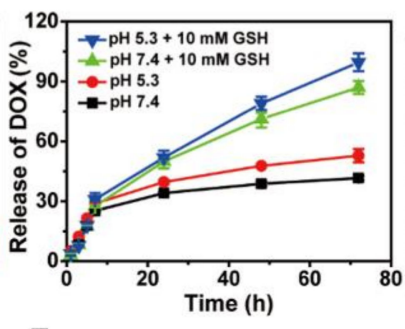

E $10 \mathrm{~min}$

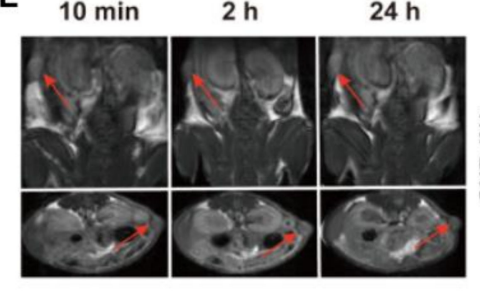

C

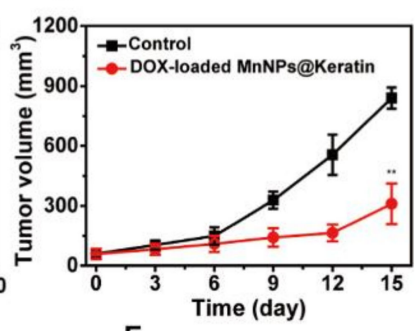

F

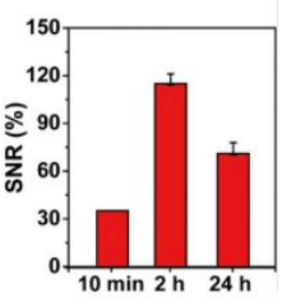

Figure 12. (A) Cell viability of $4 \mathrm{~T} 1$ incubated with different concentrations of DOX and DOX-loaded MnNPs@Keratin by CCK-8 assay; (B) release profiles of DOX from DOX-loaded MnNPs@Keratin under varying conditions mimicking the normal fluid and tumor environment; $(\mathbf{C})$ tumor volume growth curves of $4 \mathrm{~T} 1$ tumor-bearing mice after treatment with DOX-loaded MnNPs@Keratin. The mice without treatment were used as control. ${ }^{* *} p<0.01$; ${ }^{* *} p<0.001$; (D) In vivo biodistribution study; (E) T1-weighted MR images of 4T1 tumor-bearing mice after $10 \mathrm{~min}$ and 2 and $24 \mathrm{~h}$ administrations of MnNPs@Keratin $(100 \mu \mathrm{L}, 33 \mathrm{mg} / \mathrm{mL})$. Top is coronal images, and bottom is transverse images. The tumor regions are marked with red arrows; (F) T1-weighted MR signals (SNR) in the tumor calculated according to the transverse MR images. Adapted with permission from [75]. Copyright 2021 American Chemical Society.

Biodegradable KNPs made from chicken feathers have also been exploited to absorb, on their surface, antimicrobial metal ions, e.g., silver, copper, and zinc, aimed at inducing an antimicrobial effect against Gram+ and Gram- bacteria. All KNPs metal ion complexes showed an average hydrodynamic diameter of about $80 \mathrm{~nm}$ and demonstrated a strong bactericidal activity against foodborne pathogenic bacteria, E. coli and L. monocytogenes [76]. Due to the relatively low quantity of metals used, these KNPs could have a modest environmental impact, making them attractive for food packaging and biomedical applications fields.

The wastewater removal of untreated antibiotics, excreted with feces and urine, is currently challenging because of their microbial toxicity that may lead to the development of bacterial resistance phenomena, seriously threatening the ecosystem and public health. To remove norfloxacin, a broad-spectrum fluoroquinolone, Chao et al. proposed, through an eco-friendly procedure, the use of in situ generated KNPs [77]. Feathers were dissolved by using a mixture of $\mathrm{KOH}$ and Deep Eutectic Solvents at $90^{\circ} \mathrm{C}$, leading to KPNs formation. As well as residual antibiotics occur in water waste, copper contamination in drinking water also represents one of the most critical environmental issue. In this regard, keratin has been found to be applicable as a biosorbent for $\mathrm{Cu}$ (II) removal from contaminated water; in particular, thanks to the high surface area, feathers KNPs at a dosage of $3.0 \mathrm{~g} / \mathrm{L}$ displayed impressive $\mathrm{Cu}$ (II) absorption properties [78]. In addition, Mousavi et al. prepared a core-shell nanocomposite of superparamagnetic $\mathrm{Fe}_{3} \mathrm{O}_{4}$ nanoparticles with a mean keratin shell thickness of about $1.3 \mathrm{~nm}$ (MKNPs), capable of removing up to $98 \%$ of $\mathrm{Cu}$ (II) from water [21]. MKNPs were synthesized using the co-precipitation method and revealed a mean diameter of $15.0 \mathrm{~nm}$ and $8.4 \%$ of the nanocomposite weight was assigned to feather keratin. 


\section{Pros and Cons about Keratin as Natural Biomaterial for Nanoparticles Production}

Millions of tons of keratin-based biomasses are produced yearly, primarily deriving from the food and wool industries and slaughterhouses. Due to the peculiar properties of these wastes, their disposal poses several issues in terms of soil, air, and water pollution. Therefore, as for other harmful wastes, companies and research institutions have focused on developing alternative uses of keratinous biomasses to reduce their health and environmental impact. Most of these activities have been based on the extraction of keratin to be used for different applications, especially in biomedical devices and drug carriers' fabrication.

In particular, the last decades have witnessed a mounting interest in using keratin wastes as a renewable source for nanoparticle production. Indeed, keratin represents a highly abundant, biodegradable, non-toxic, biocompatible, and versatile biopolymer with very appealing physical and mechanical properties, such as strength, stability, and resistance to proteolytic degradation. Moreover, exploiting the protein hydrophobic and hydrophilic domains and the presence of several chemical moieties $\left(-\mathrm{NH}_{2},-\mathrm{COOH}\right.$, and $-\mathrm{SH})$, keratin allows the incorporation or the covalent attachment of different molecules (drugs, targeting moieties, dyes).

Furthermore, the RGD and LDV sequences on the protein backbone could ensure a certain degree of intrinsic tumor-targeting ability by specifically binding the vitronectin integrin receptors overexpressed in cancer cells. Finally, the presence of high percentages of Cys amino acids translates into a high number of intermolecular disulfide bridges. This feature, which represents a disadvantage if considering keratin waste disposal, can be exploited effectively for the controlled release of drugs at the tumor site.

On the other side of the coin, due to keratin's poor water solubility, disulfide bridges and hydrogen inter-chain bonds must be cleaved through harsh extracting conditions, but finding an effective and environmentally friendly procedure remains an open challenge. Indeed, one further major issue arising from our analysis correlates to extraction procedures, which suffer from high variability and poor data availability on the isolated protein in terms of purity, average molecular weight, genotoxicity, and scale-up feasibility. This ultimately poses severe regulatory issues for keratin exploitation in the biomedical field.

To summarize, using keratin as drug delivery carrier could represent a remarkable breakthrough in the field of (cancer) nanomedicine, mainly because of the natural features of this fascinating protein, such as its extraordinary drug loading ability, versatility, and functionalization properties. On the other hand, difficulties in extraction and standardization procedures still require consistent efforts both from the research and the industrial communities to bring this biomaterial closer to clinical translation.

\section{Conclusions}

In this work, we aimed at giving an overview of the research papers describing the production and use of keratin-based nanoparticles as carriers of anticancer and antimicrobial drugs, as well as for wound healing applications.

Keratin-mediated delivery has revealed benefits for multiple kinds of drugs, since the protein intrinsic characteristics, such as good $\mathrm{pH}$ and GSH responsiveness, biocompatibility and biodegradability, cells adhesion properties, and affinity towards hydrophobic and hydrophilic drugs, represent important features for a single biomaterial, deserving more systematic research of its most suitable applications for a concrete clinical translation.

Ongoing and future studies are expected to elucidate how keratin binding impacts cellular entry and the following intracellular trafficking of its drug cargo. Moving forward, it will be necessary to investigate and eventually understand possible immunogenic reactions triggered by keratin nanoparticles' exposure, as well as their pharmacodynamic and pharmacokinetics profiles. In our opinion, the number of advantages of using keratin carriers outperforms the disadvantages, thus making this research field worth more extensive investigations and investments. 
Author Contributions: Writing-original draft preparation, C.F. and G.V.; writing-review and editing, C.F. and G.V. All authors have read and agreed to the published version of the manuscript."

Funding: This research received no external funding.

Institutional Review Board Statement: Not applicable.

Informed Consent Statement: Not applicable.

Data Availability Statement: Not applicable.

Conflicts of Interest: The authors declare no conflict of interest.

\section{References}

1. Anselmo, A.; Mitragotri, S. An overview of clinical and commercial impact of drug delivery systems. J. Control. Release 2014, 190, 15-28. [CrossRef]

2. Finbloom, J.A.; Sousa, F.; Stevens, M.M.; Desai, T.A. Engineering the drug carrier biointerface to overcome biological barriers to drug delivery. Adv. Drug Deliv. Rev. 2020, 167, 89-108. [CrossRef]

3. Jahangirian, H.; Lemraski, E.G.; Webster, T.J.; Rafiee-Moghaddam, R.; Abdollahi, Y. A review of drug delivery systems based on nanotechnology and green chemistry: Green nanomedicine. Int. J. Nanomed. 2017, 12, 2957-2978. [CrossRef]

4. Varanko, A.; Saha, S.; Chilkoti, A. Recent trends in protein and peptide-based biomaterials for advanced drug delivery. Adv. Drug Deliv. Rev. 2020, 156, 133-187. [CrossRef] [PubMed]

5. Reddy, C.C.; Khilji, I.A.; Gupta, A.; Bhuyar, P.; Mahmood, S.; Al-Japairai, K.A.S.; Chua, G.K. Valorization of keratin waste biomass and its potential applications. J. Water Process. Eng. 2021, 40, 101707. [CrossRef]

6. Xu, S.; Sang, L.; Zhang, P.; Wang, X.; Li, X. Biological evaluation of human hair keratin scaffolds for skin wound repair and regeneration. Mater. Sci. Eng. C 2013, 33, 648-655. [CrossRef] [PubMed]

7. Feroz, S.; Muhammad, N.; Ratnayake, J.; Dias, G. Keratin-Based materials for biomedical applications. Bioact. Mater. 2020, 5, 496-509. [CrossRef] [PubMed]

8. Holkar, C.; Jain, S.S.; Jadhav, A.; Pinjari, D.V. Valorization of keratin based waste. Process. Saf. Environ. Prot. 2018, 115, 85-98. [CrossRef]

9. Vineis, C.; Varesano, A.; Varchi, G.; Aluigi, A. Extraction and Characterization of Keratin from Different Biomasses. In Keratin as a Protein Biopolymer; Sharma, S., Kumar, A., Eds.; Springer Series on Polymer and Composite Materials; Springer Nature: Cham, Switzerland, 2019; pp. 35-76. [CrossRef]

10. Bheel, N.; Awoyera, P.; Aluko, O.; Mahro, S.; Viloria, A.; Sierra, C.A.S. Sustainable composite development: Novel use of human hair as fiber in concrete. Case Stud. Constr. Mater. 2020, 13, e00412. [CrossRef]

11. Seghir, B.B.; Hemmami, H.; Zeghoud, S.; Laouini, S.E.; Rebiai, A.; Amor, I.B.; Souici, I.; Beki, A. Preparation methods keratin and nanoparticles keratin from wool: A review. Alger. J. Chem. Eng. 2020, 1, 5-11.

12. Agarwal, V.; Panicker, A.G.; Indrakumar, S.; Chatterjee, K. Comparative study of keratin extraction from human hair. Int. J. Biol. Macromol. 2019, 133, 382-390. [CrossRef]

13. Cassoni, A.C.; Freixo, R.; Pintado, A.I.E.; Amorim, M.; Pereira, C.D.; Madureira, A.R.; Pintado, M.M.E. Novel Eco-Friendly Method to Extract Keratin from Hair. ACS Sustain. Chem. Eng. 2018, 6, 12268-12274. [CrossRef]

14. Alahyaribeik, S.; Ullah, A. Methods of keratin extraction from poultry feathers and their effects on antioxidant activity of extracted keratin. Int. J. Biol. Macromol. 2020, 148, 449-456. [CrossRef] [PubMed]

15. Ebrahimgol, F.; Tavanai, H.; Alihosseini, F.; Khayamian, T. Electrosprayed recovered wool keratin nanoparticles. Polym. Adv. Technol. 2014, 25, 1001-1007. [CrossRef]

16. Zhi, X.; Wang, Y.; Li, P.; Yuan, J.; Shen, J. Preparation of keratin/chlorhexidine complex nanoparticles for long-term and dual stimuli-responsive release. RSC Adv. 2015, 5, 82334-82341. [CrossRef]

17. Liu, J.; Zheng, J.; Rao, H. Preparation and drug-loading properties of human hair keratin nanoparticles. Int. J. Sci. 2017, 4, 93-96.

18. Martella, E.; Ferroni, C.; Guerrini, A.; Ballestri, M.; Columbaro, M.; Santi, S.; Sotgiu, G.; Serra, M.; Donati, D.M.; Lucarelli, E.; et al. Functionalized Keratin as Nanotechnology-Based Drug Delivery System for the Pharmacological Treatment of Osteosarcoma. Int. J. Mol. Sci. 2018, 19, 3670. [CrossRef] [PubMed]

19. Liu, P.; Wu, Q.; Li, Y.; Li, P.; Yuan, J.; Meng, X.; Xiao, Y. DOX-Conjugated keratin nanoparticles for pH-Sensitive drug delivery. Colloids Surf. B Biointerfaces 2019, 181, 1012-1018. [CrossRef] [PubMed]

20. Ghaffari, R.; Eslahi, N.; Tamjid, E.; Simchi, A.A. Dual-Sensitive Hydrogel Nanoparticles Based on Conjugated Thermoresponsive Copolymers and Protein Filaments for Triggerable Drug Delivery. ACS Appl. Mater. Interfaces 2018, 10, 19336-19346. [CrossRef]

21. Mousavi, S.Z.; Manteghian, M.; Shojaosadati, S.A.; Pahlavanzadeh, H. Preparation and characterization of magnetic keratin nanocomposite. Mater. Chem. Phys. 2018, 215, 40-45. [CrossRef]

22. Gupta, A. Human Hair "Waste" and Its Utilization: Gaps and Possibilities. J. Waste Manag. 2014, 1-17. [CrossRef]

23. McLellan, J.; Thornhill, S.G.; Shelton, S.; Kumar, M. Keratin-Based Biofilms, Hydrogels, and Biofibers. Keratin-based biofilms, hydrogels, and biofibers. In Keratin as a Protein Biopolymer; Springer: Cham, Switzerland, 2019; pp. 187-200. [CrossRef] 
24. Brown, E.M.; Pandya, K.; Taylor, M.M.; Liu, C.-K. Comparison of Methods for Extraction of Keratin from Waste Wool. Agric. Sci. 2016, 7, 670-679. [CrossRef]

25. Yi, Z.; Cui, X.; Chen, G.; Chen, X.; Jiang, X.; Li, X. Biocompatible, Antioxidant Nanoparticles Prepared from Natural Renewable Tea Polyphenols and Human Hair Keratins for Cell Protection and Anti-inflammation. ACS Biomater. Sci. Eng. 2021, 7, $1046-1057$. [CrossRef] [PubMed]

26. Du, J.; Wang, L.; Han, X.; Dou, J.; Jiang, X.; Yuan, J. Polydopamine/keratin complexes as gatekeepers of mesoporous silica nanoparticles for $\mathrm{pH}$ and GSH dual responsive drug delivery. Mater. Lett. 2021, 293, 129676. [CrossRef]

27. Thilagam, R.; Gnanamani, A. Preparation, characterization and stability assessment of keratin and albumin functionalized gold nanoparticles for biomedical applications. Appl. Nanosci. 2020, 10, 1879-1892. [CrossRef]

28. Galicia-Garcia, U.; Benito-Vicente, A.; Jebari, S.; Larrea-Sebal, A.; Siddiqi, H.; Uribe, K.B.; Ostolaza, H.; Martín, C. Pathophysiology of Type 2 Diabetes Mellitus. Int. J. Mol. Sci. 2020, 21, 6275. [CrossRef] [PubMed]

29. Kunjiappan, S.; Theivendren, P.; Pavadai, P.; Govindaraj, S.; Sankaranarayanan, M.; Somasundaram, B.; Arunachalam, S.; Pandian, S.R.K.; Ammunje, D.N.; Parasuraman, P. Design and in silico modeling of Indoloquinoxaline incorporated keratin nanoparticles for modulation of glucose metabolism in 3T3-L1 adipocytes. Biotechnol. Prog. 2020, 36, e2904. [CrossRef]

30. Rondinone, C.M.; Trevillyan, J.M.; Clampit, J.; Gum, R.J.; Berg, C.; Kroeger, P.; Frost, L.; Zinker, B.A.; Reilly, R.; Ulrich, R.; et al. Protein tyrosine phosphatase 1B reduction regulates adiposity and expression of genes involved in lipogenesis. Diabetes 2002, 51, 2405-2411. [CrossRef] [PubMed]

31. Hardie, D.G. Adenosine monophosphate-activated protein kinase: A central regulator of metabolism with roles in diabetes, cancer, and viral infection. Cold Spring Harb. Symp. Quant. Biol. 2011, 76, 155-164. [CrossRef]

32. Cañedo-Dorantes, L.; Cañedo-Ayala, M. Skin Acute Wound Healing: A Comprehensive Review. Int. J. Inflamm. 2019, 2019 , 1-15. [CrossRef]

33. Boateng, J. (Ed.) Therapeutic Dressings and Wound Healing Applications; John Wiley and Sons Ltd.: Hoboken, NJ, USA, 2020. [CrossRef]

34. Li, W.; Gao, F.; Kan, J.; Deng, J.; Wang, B.; Hao, S. Synthesis and fabrication of a keratin-conjugated insulin hydrogel for the enhancement of wound healing. Colloids Surf. B Biointerfaces 2019, 175, 436-444. [CrossRef] [PubMed]

35. Gao, F.; Li, W.; Deng, J.; Kan, J.; Guo, T.; Wang, B.; Hao, S. Recombinant Human Hair Keratin Nanoparticles Accelerate Dermal Wound Healing. ACS Appl. Mater. Interfaces 2019, 11, 18681-18690. [CrossRef]

36. Kunjiappan, S.; Panneerselvam, T.; Somasundaram, B.; Sankaranarayanan, M.; Chowdhury, R.; Chowdhury, A.; Bhattacharjee, C. Design, in silico modeling, biodistribution study of rutin and quercetin loaded stable human hair keratin nanoparticles intended for anticancer drug delivery. Biomed. Phys. Eng. Express 2017, 4, 025019. [CrossRef]

37. Tang, S.-M.; Deng, X.-T.; Zhou, J.; Li, Q.-P.; Ge, X.-X.; Miao, L. Pharmacological basis and new insights of quercetin action in respect to its anti-cancer effects. Biomed. Pharmacother. 2020, 121, 109604. [CrossRef] [PubMed]

38. Kunjiappan, S.; Chowdhury, A.; Somasundaram, B.; Bhattacharjee, C.; Periyasamy, S. Optimization, preparation and characterization of rutin-quercetin dual drug loaded keratin nanoparticles for biological applications. Nanomed. J. 2016, 3, $253-267$.

39. Masoodi, T.; Alhamdanz, A.H. Inhibitory effect of flavonoids on mutant H-Rasp21 protein. Bioinformation 2010, 5, 11-15. [CrossRef]

40. Boddupalli, B.M.; Mohammed, Z.N.K.; Nath, R.A.; Banji, D. Mucoadhesive drug delivery system: An overview. J. Adv. Pharm. Technol. Res. 2010, 1, 381. [CrossRef]

41. Mansuri, S.; Kesharwani, P.; Jain, K.; Tekade, R.K.; Jain, N. Mucoadhesion: A promising approach in drug delivery system. React. Funct. Polym. 2016, 100, 151-172. [CrossRef]

42. Cheng, Z.; Chen, X.; Zhai, D.; Gao, F.; Guo, T.; Li, W.; Hao, S.; Ji, J.; Wang, B. Development of keratin nanoparticles for controlled gastric mucoadhesion and drug release. J. Nanobiotechnol. 2018, 16, 1-13. [CrossRef]

43. Luo, T.; Hao, S.; Chen, X.; Wang, J.; Yang, Q.; Wang, Y.; Weng, Y.; Wei, H.; Zhou, J.; Wang, B. Development and assessment of kerateine nanoparticles for use as a hemostatic agent. Mater. Sci. Eng. C 2016, 63, 352-358. [CrossRef]

44. Karpinski, T.; Szkaradkiewicz, A.K. Chlorhexidine-pharmaco-biological activity and application. Eur. Rev. Med. Pharmacol. Sci. 2015, 19, 1321-1326.

45. Isemura, M.; Miyoshi, N.; Pervin, M.; Suzuki, T.; Unno, K.; Nakamura, Y. Green tea catechins for well-being and therapy: Prospects and opportunities. Bot. Targets Ther. 2015, 5, 85-96. [CrossRef]

46. Yi, Z.; Sun, Z.; Chen, G.; Zhang, H.; Ma, X.; Su, W.; Cui, X.; Li, X. Size-controlled, colloidally stable and functional nanoparticles based on the molecular assembly of green tea polyphenols and keratins for cancer therapy. J. Mater. Chem. B 2018, 6, 1373-1386. [CrossRef] [PubMed]

47. Wang, L.; Du, J.; Han, X.; Dou, J.; Shen, J.; Yuan, J. Self-crosslinked keratin nanoparticles for pH and GSH dual responsive drug carriers. J. Biomater. Sci. Polym. Ed. 2020, 31, 1-13. [CrossRef] [PubMed]

48. Han, X.; Wang, L.; Du, J.; Dou, J.; Yuan, J.; Shen, J. Keratin-dopamine conjugate nanoparticles as pH/GSH dual responsive drug carriers. J. Biomater. Sci. Polym. Ed. 2020, 31, 2318-2330. [CrossRef] [PubMed]

49. Pozzo, L.D.Y.; da Conceição, T.F.; Spinelli, A.; Scharnagl, N.; Pires, A.T. Chitosan coatings crosslinked with genipin for corrosion protection of AZ31 magnesium alloy sheets. Carbohydr. Polym. 2018, 181, 71-77. [CrossRef] [PubMed]

50. Sun, Z.; Yi, Z.; Cui, X.; Chen, X.; Su, W.; Ren, X.; Li, X. Tumor-targeted and nitric oxide-generated nanogels of keratin and hyaluronan for enhanced cancer therapy. Nanoscale 2018, 10, 12109-12122. [CrossRef] 
51. Li, Y.; Lin, J.; Zhi, X.; Li, P.; Jiang, X.; Yuan, J. Triple stimuli-responsive keratin nanoparticles as carriers for drug and potential nitric oxide release. Mater. Sci. Eng. C 2018, 91, 606-614. [CrossRef] [PubMed]

52. Du, J.; Wang, L.; Han, X.; Dou, J.; Yuan, J.; Shen, J. Keratin-tannic acid complex nanoparticles as pH/GSH dual responsive drug carriers for doxorubicin. J. Biomater. Sci. Polym. Ed. 2021, 32, 1-10. [CrossRef] [PubMed]

53. Li, Y.; Zhi, X.; Lin, J.; You, X.; Yuan, J. Preparation and characterization of DOX loaded keratin nanoparticles for $\mathrm{pH} / \mathrm{GSH}$ dual responsive release. Mater. Sci. Eng. C 2017, 73, 189-197. [CrossRef]

54. Zhi, X.; Liu, P.; Li, Y.; Li, P.; Yuan, J.; Lin, J. One-step fabricated keratin nanoparticles as $\mathrm{pH}$ and redox-responsive drug nanocarriers. J. Biomater. Sci. Polym. Ed. 2018, 29, 1920-1934. [CrossRef] [PubMed]

55. Luzi, F.; Puglia, D.; Torre, L. Natural fiber biodegradable composites and nanocomposites. In Biomass, Biopolymer-Based Materials, and Bioenergy; Elsevier: Amsterdam, The Netherlands, 2019; pp. 179-201. [CrossRef]

56. Cilurzo, F.; Selmin, F.; Aluigi, A.; Bellosta, S. Regenerated keratin proteins as potential biomaterial for drug delivery. Polym. Adv. Technol. 2013, 24, 1025-1028. [CrossRef]

57. Aluigi, A.; Sotgiu, G.; Ferroni, C.; Duchi, S.; Lucarelli, E.; Martini, C.; Posati, T.; Guerrini, A.; Ballestri, M.; Corticelli, F.; et al. Chlorin e6 keratin nanoparticles for photodynamic anticancer therapy. RSC Adv. 2016, 6, 33910-33918.

58. Foglietta, F.; Spagnoli, G.C.; Muraro, M.G.; Ballestri, M.; Guerrini, A.; Ferroni, C.; Aluigi, A.; Sotgiu, G.; Varchi, G. Anticancer activity of paclitaxel-loaded keratin nanoparticles in two-dimensional and perfused three-dimensional breast cancer models. Int. J. Nanomed. 2018, 13, 4847-4867. [CrossRef]

59. Busi, A.; Aluigi, A.; Guerrini, A.; Boga, C.; Sartor, G.; Calonghi, N.; Sotgiu, G.; Posati, T.; Corticelli, F.; Fiori, J.; et al. Unprecedented Behavior of (9R)-9-Hydroxystearic Acid-Loaded Keratin Nanoparticles on Cancer Cell Cycle. Mol. Pharm. 2019, 16, 931-942. [CrossRef]

60. Aluigi, A.; Ballestri, M.; Guerrini, A.; Sotgiu, G.; Ferroni, C.; Corticelli, F.; Gariboldi, M.B.; Monti, E.; Varchi, G. Organic solventfree preparation of keratin nanoparticles as doxorubicin carriers for antitumour activity. Mater. Sci. Eng. C 2018, 90, 476-484. [CrossRef]

61. Li, Q.; Zhu, L.; Liu, R.; Huang, D.; Jin, X.; Che, N.; Li, Z.; Qu, X.; Kang, H.; Huang, Y. Biological stimuli responsive drug carriers based on keratin for triggerable drug delivery. J. Mater. Chem. 2012, 22, 19964-19973. [CrossRef]

62. Curcio, M.; Blanco-Fernandez, B.; Diaz-Gomez, L.; Concheiro, A.; Alvarez-Lorenzo, C. Hydrophobically Modified Keratin Vesicles for GSH-Responsive Intracellular Drug Release. Bioconj. Chem. 2015, 26, 1900-1907. [CrossRef]

63. Perotto, G.; Sandri, G.; Pignatelli, C.; Milanesi, G.; Athanassiou, A. Water-based synthesis of keratin micro- and nanoparticles with tunable mucoadhesive properties for drug delivery. J. Mater. Chem. B 2019, 7, 4385-4392. [CrossRef]

64. Erdoğan, M.K.; Tı̆̆g, G.A.; Saçak, M. A novel tool for the adsorption of dsDNA: Electrochemical reduction of Pd nanoparticles onto reduced-keratin particles extracted from wool wastes. Bioelectrochemistry 2021, 140, 107835. [CrossRef] [PubMed]

65. Guglielmelli, A.; Rosa, P.; Contardi, M.; Prato, M.; Mangino, G.; Miglietta, S.; Petrozza, V.; Pani, R.; Calogero, A.; Athanassiou, A.; et al. Biomimetic keratin gold nanoparticle-mediated in vitro photothermal therapy on glioblastoma multiforme. Nanomedicine 2021, 16, 121-138. [CrossRef] [PubMed]

66. Tesfaye, T.; Sithole, B.; Ramjugernath, D.; Chunilall, V. Valorisation of chicken feathers: Characterisation of chemical properties. Waste Manag. 2017, 68, 626-635. [CrossRef] [PubMed]

67. Hemashree, T.; Prasunna, S.G.; Sakthiselvan, P. Synthesis of Keratin Nanoparticle and Characterization using FTIR. Res. J. Pharm. Technol. 2019, 12, 2664. [CrossRef]

68. Rad, Z.P.; Tavanai, H.; Moradi, A. Production of feather keratin nanopowder through electrospraying. J. Aerosol Sci. 2012, 51, 49-56. [CrossRef]

69. Xu, H.; Shi, Z.; Reddy, N.; Yang, Y. Intrinsically Water-Stable Keratin Nanoparticles and Their in Vivo Biodistribution for Targeted Delivery. J. Agric. Food Chem. 2014, 62, 9145-9150. [CrossRef]

70. Saravanan, S.; Sameera, D.; Moorthi, A.; Selvamurugan, N. Chitosan scaffolds containing chicken feather keratin nanoparticles for bone tissue engineering. Int. J. Biol. Macromol. 2013, 62, 481-486. [CrossRef] [PubMed]

71. Wang, J.; Hao, S.; Luo, T.; Yang, Q.; Wang, B. Development of feather keratin nanoparticles and investigation of their hemostatic efficacy. Mater. Sci. Eng. C 2016, 68, 768-773. [CrossRef]

72. Sharma, S.; Gupta, A.; Chik, S.M.S.; Kee, C.G.; Mistry, B.M.; Kim, D.H.; Sharma, G. Characterization of keratin microparticles from feather biomass with potent antioxidant and anticancer activities. Int. J. Biol. Macromol. 2017, 104, 189-196. [CrossRef]

73. Zhang, H.; Pei, M.; Liu, P. Keratin-based drug-protein conjugate with acid-labile and reduction-cleavable linkages in series for tumor intracellular DOX delivery. J. Ind. Eng. Chem. 2019, 80, 739-748. [CrossRef]

74. Zhang, H.; Liu, P. One-Pot Synthesis of Chicken-Feather-Keratin-Based Prodrug Nanoparticles with High Drug Content for Tumor Intracellular DOX Delivery. Langmuir 2019, 35, 8007-8014. [CrossRef]

75. Li, Y.; Song, K.; Cao, Y.; Peng, C.; Yang, G. Keratin-Templated Synthesis of Metallic Oxide Nanoparticles as MRI Contrast Agents and Drug Carriers. ACS Appl. Mater. Interfaces 2018, 10, 26039-26045. [CrossRef]

76. Shankar, S.; Rhim, J.-W. Eco-friendly antimicrobial nanoparticles of keratin-metal ion complex. Mater. Sci. Eng. C 2019, 105, 110068. [CrossRef] [PubMed] 
77. Chao, S.-J.; Chung, K.-H.; Lai, Y.-F.; Lai, Y.-K.; Chang, S.-H. Keratin particles generated from rapid hydrolysis of waste feathers with green DES/KOH: Efficient adsorption of fluoroquinolone antibiotic and its reuse. Int. J. Biol. Macromol. 2021, 173, 211-218. [CrossRef]

78. Zahra, S.; Manteghian, M.; Abbas, S.; Pahlavanzadeh, H. Keratin nanoparticles: Synthesis and application for Cu (II) removal. Adv. Environ. Technol. 2018, 4, 83-93. 